\title{
Light extinction by secondary organic aerosol: an intercomparison of three broadband cavity spectrometers
}

\author{
R. M. Varma ${ }^{1,2,3}$, S. M. Ball ${ }^{4}$, T. Brauers ${ }^{5}$, H.-P. Dorn ${ }^{5}$, U. Heitmann ${ }^{2}$, R. L. Jones ${ }^{6}$, U. Platt ${ }^{7}$, D. Pöhler ${ }^{7}$, A. A. Ruth ${ }^{2}$, \\ A. J. L. Shillings ${ }^{6}$, J. Thieser ${ }^{7,8}$, A. Wahner ${ }^{5}$, and D. S. Venables ${ }^{1}$ \\ ${ }^{1}$ Department of Chemistry and Environmental Research Institute, University College Cork, Cork, Ireland \\ ${ }^{2}$ Department of Physics and Environmental Research Institute, University College Cork, Cork, Ireland \\ ${ }^{3}$ Department of Physics, National Institute of Technology Calicut, Kerala, India \\ ${ }^{4}$ Department of Chemistry, University of Leicester, Leicester, LE1 7RH, UK \\ ${ }^{5}$ Institute of Energy and Climate Research, IEK-8: Troposphere, Forschungszentrum Jülich, Jülich, Germany \\ ${ }^{6}$ Department of Chemistry, University of Cambridge, Cambridge, CB2 1EW, UK \\ ${ }^{7}$ Institute of Environmental Physics, University of Heidelberg, Heidelberg, Germany \\ ${ }^{8}$ Max-Planck-Institut für Chemie, Division of Atmospheric Chemistry, Mainz, Germany
}

Correspondence to: D. S. Venables (d.venables@ucc.ie)

Received: 20 June 2013 - Published in Atmos. Meas. Tech. Discuss.: 22 July 2013

Revised: 17 October 2013 - Accepted: 24 October 2013 - Published: 19 November 2013

\begin{abstract}
Broadband optical cavity spectrometers are maturing as a technology for trace-gas detection, but only recently have they been used to retrieve the extinction coefficient of aerosols. Sensitive broadband extinction measurements allow explicit separation of gas and particle phase spectral contributions, as well as continuous spectral measurements of aerosol extinction in favourable cases. In this work, we report an intercomparison study of the aerosol extinction coefficients measured by three such instruments: a broadband cavity ring-down spectrometer (BBCRDS), a cavity-enhanced differential optical absorption spectrometer (CE-DOAS), and an incoherent broadband cavity-enhanced absorption spectrometer (IBBCEAS). Experiments were carried out in the SAPHIR atmospheric simulation chamber as part of the NO3Comp campaign to compare the measurement capabilities of $\mathrm{NO}_{3}$ and $\mathrm{N}_{2} \mathrm{O}_{5}$ instrumentation. Aerosol extinction coefficients between 655 and $690 \mathrm{~nm}$ are reported for secondary organic aerosols (SOA) formed by the $\mathrm{NO}_{3}$ oxidation of $\beta$-pinene under dry and humid conditions. Despite different measurement approaches and spectral analysis procedures, the three instruments retrieved aerosol extinction coefficients that were in close agreement. The refractive index of SOA formed from the $\beta$-pinene $+\mathrm{NO}_{3}$ reaction was 1.61 , and was not measurably affected by the chamber humidity or by aging of the aerosol over several hours. This
\end{abstract}

refractive index is significantly larger than SOA refractive indices observed in other studies of $\mathrm{OH}$ and ozone-initiated terpene oxidations, and may be caused by the large proportion of organic nitrates in the particle phase. In an experiment involving ammonium sulfate particles, the aerosol extinction coefficients as measured by IBBCEAS were found to be in reasonable agreement with those calculated using the Mie theory. The results of the study demonstrate the potential of broadband cavity spectrometers for determining the optical properties of aerosols.

\section{Introduction}

The contribution of suspended atmospheric particles to radiative forcing is both large and poorly constrained (Forster et al., 2007; Menon, 2004). The aerosol extinction (i.e. the optical loss per unit length along a light path due to absorption and scattering of light by particles) is usually dominated by scattering. Nevertheless, absorption of light by particles is important in many contexts and has recently attracted much attention (Andreae and Gelencser, 2006; Bergstrom et al., 2007; Myhre, 2009; Martins et al., 2009; Jacobson, 1999; Alexander et al., 2008; Mellon et al., 2011). To better quantify the influence of atmospheric particles on radiative 
forcing, further characterization of their optical properties is necessary.

Current approaches for studying the optical properties of particles are mainly limited in two respects: firstly, significant experimental artefacts and lack of agreement are associated with some aerosol absorption measurements (Kirchstetter et al., 2004; Andreae and Gelencser, 2006). Secondly, aerosol optical properties are often not available at ultraviolet wavelengths (where the absorption of carbonaceous aerosols sometimes increases strongly); this incomplete spectral information limits assessment of the aerosol influence on radiative balance and tropospheric photochemistry (Martins et al., 2009; Bergstrom et al., 2007; Hoffer et al., 2006; Andreae and Gelencser, 2006). Several studies have therefore called for new approaches to measuring the optical absorption of particulate matter in the atmosphere (Hallquist et al., 2009; Andreae and Gelencser, 2006; Kirchstetter et al., 2004).

Over the last decade, optical cavity methods have greatly advanced the characterization of aerosols (Pettersson et al., 2004; Moosmüller et al., 2009; Miles et al., 2011; Abo Riziq et al., 2007). The high sensitivity of these methods results from the very long effective path lengths - typically hundreds of metres to tens of kilometres - that are achieved inside high-finesse optical cavities. Sensitive and accurate aerosol extinction coefficient measurements can also be combined with a separate measurement of the scattering coefficient in the so-called extinction-minus-scattering approach to retrieve the aerosol absorption. Cavity ring-down spectroscopy (CRDS) has been used by several groups for laboratory, field, and airborne studies of aerosol optical properties (Smith and Atkinson, 2001; Moosmüller et al., 2005; Strawa et al., 2003; Thompson et al., 2002; Ma and Thompson, 2012). Extinction coefficient detection limits of well below $1 \mathrm{Mm}^{-1}$ (equivalent to $10^{-8} \mathrm{~cm}^{-1}$ ) have been demonstrated with CRDS systems (Moosmüller et al., 2009). A related method, cavity attenuated phase shift (CAPS) spectroscopy, has also been used for quantifying aerosol extinction over a narrow wavelength band (Kebabian et al., 2007; Massoli et al., 2010). Although Miles et al. (2010) have recently demonstrated a CRDS system for measuring aerosol extinction spectra, typical CRDS and CAPS system are limited to one or two wavelengths; moreover, care must be taken to account for gas absorption when quantifying the aerosol extinction.

Richer spectral information can be acquired by combining optical cavities with broadband light sources (Ball and Jones, 2003; Bitter et al., 2005; Venables et al., 2006; Platt et al., 2009; Ruth et al., 2014). As with laser-based CRDS, this approach was first applied to trace-gas detection but has since been extended to quantify aerosol extinction. Early work with broadband light sources and optical cavities focussed on single wavelength or passband measurements. Thompson and Spangler (2006) spectrally integrated the intensity of an incandescent tungsten bulb through an optical cavity to monitor aerosol extinction. Varma et al. (2009) used the fractional absorption of the $\mathrm{O}_{2}$ B-band to quantify the total extinction of the sample at $687 \mathrm{~nm}$, and subsequently retrieved the aerosol extinction after removing the small contribution of gas-phase absorption. Thalman and Volkamer (2010) similarly quantified the aerosol extinction at blue wavelengths based on the $\mathrm{O}_{2}$-dimer absorption at $477 \mathrm{~nm}$ or the $\mathrm{H}_{2} \mathrm{O}$ absorption at $443 \mathrm{~nm}$. As demonstrated below, it is also possible to determine the aerosol extinction directly at an arbitrary wavelength if absorption by gases can be accounted for. Broadband optical cavity methods do not attain the sensitivity of typical CRDS and other laser-based cavity approaches, but crucially their spectral information allows absorbing gases to be quantified and their absorption contribution to the total sample extinction removed, thereby permitting the underlying aerosol extinction to be quantified. The method is also readily extended to different wavelength regions - particularly to shorter wavelengths where aerosol absorption often increases (Andreae and Gelencser, 2006; Kirchstetter et al., 2004; Chen and Bond, 2010; Hoffer et al., 2006; Martins et al., 2009). Very recently, several groups have started to exploit the potential of broadband cavity systems to achieve both spectrally continuous measurements of aerosol extinction and to perform measurements at short visible and ultraviolet wavelengths (Zhao et al., 2013; Washenfelder et al., 2013; Wilson et al., 2013).

In June 2007, three broadband optical cavity systems took part in an intercomparison study at the SAPHIR atmosphere simulation chamber. Although the primary focus of the campaign was to compare instrumental performance in measuring $\mathrm{NO}_{3}$ (Dorn et al., 2013) and $\mathrm{N}_{2} \mathrm{O}_{5}$ (Fuchs et al., 2012), the optical extinction due to particles in the chamber was also retrieved by the broadband instruments. In this study, we report the aerosol extinction coefficients on four days of the campaign, and compare the instruments' performance and different analytical approaches used to retrieve the aerosol extinction coefficients. For the instrument with the most extensive data set, we compare extinction coefficients measured for ammonium sulfate aerosols with the Mie theory calculations and assess the instrument's long-term stability. Finally, we report for the first time the refractive index of the secondary organic aerosol (SOA) produced by $\mathrm{NO}_{3}$ oxidation of $\beta$-pinene.

\section{Experimental}

The aerosol extinction coefficient measurements reported here were made during the instrument intercomparison campaign "NO3Comp" held in June 2007 at the SAPHIR atmosphere simulation chamber, located in the Forschungszentrum Jülich, Germany (Bohn et al., 2005; Rohrer et al., 2005; Brauers et al., 2007; Apel et al., 2008). The campaign was designed for the intercomparison of instruments which measure $\mathrm{NO}_{3}$ (Dorn et al., 2013) and $\mathrm{N}_{2} \mathrm{O}_{5}$ (Fuchs et al., 2012), and was subsequently broadened to include $\mathrm{NO}_{2}$ measurements 
Table 1. Operating parameters of the BBCRDS, CE-DOAS, and IBBCEAS instruments and the wavelength range of the reported aerosol extinction, $\varepsilon_{\mathrm{A}}$.

\begin{tabular}{|c|c|c|c|c|}
\hline Instrument & Cavity parameters* & $\begin{array}{r}\text { Sampling } \\
\text { time }\end{array}$ & $\begin{array}{r}\text { Spectral range } \\
\text { of } \varepsilon_{\mathrm{A}}\end{array}$ & $\begin{array}{l}\text { Uncertainty } \\
\text { in } \varepsilon_{\mathrm{A}}\end{array}$ \\
\hline $\begin{array}{l}\text { BBCRDS } \\
\text { (extractive) }\end{array}$ & $\begin{array}{l}L_{\mathrm{p}}=1.83 \mathrm{~m} \\
L_{\mathrm{S}}=1.56 \mathrm{~m} \\
L_{\mathrm{f}}=1.05 \\
R=99.996 \%(680 \mathrm{~nm})\end{array}$ & $60 s$ & $655-665 \mathrm{~nm}$ & $0.4-4 \mathrm{Mm}^{-1}$ \\
\hline $\begin{array}{l}\text { CE-DOAS } \\
\text { (open path) }\end{array}$ & $\begin{array}{l}L_{\mathrm{p}}=0.62 \mathrm{~m} \\
L_{\mathrm{S}}=0.50 \mathrm{~m} \\
R=99.9985 \%(655 \mathrm{~nm})\end{array}$ & $60 s$ & $673-677 \mathrm{~nm}$ & $10 \mathrm{Mm}^{-1}$ \\
\hline $\begin{array}{l}\text { IBBCEAS } \\
\text { (open path) }\end{array}$ & $\begin{array}{l}L_{\mathrm{p}}=20.1 \mathrm{~m} \\
L_{\mathrm{S}}=18.3 \mathrm{~m} \\
R=99.84 \%(687 \mathrm{~nm})\end{array}$ & $5 \mathrm{~s}$ & $687.0 \mathrm{~nm}$ & $10 \%$ (relative) \\
\hline
\end{tabular}

\footnotetext{
* $L_{\mathrm{p}}$ is the physical separation between the cavity mirrors, $L_{\mathrm{S}}$ is the length of the sample region in the cavity, and $R$ is the mirror reflectivity at the specified wavelength. For the BBCRDS system, the length factor, $L_{\mathrm{f}}$, is similar, but not identical, to the ratio $L_{\mathrm{p}} / L_{\mathrm{s}}$, probably owing to intrusion of sample gas into the purge region around the mirrors.
}

(Fuchs et al., 2010). Most of the instruments monitored $\mathrm{NO}_{3}$ via its absorption band at $662 \mathrm{~nm}$ using either optical cavities or multipass DOAS. Some instruments also measured $\mathrm{N}_{2} \mathrm{O}_{5}$ via its thermal dissociation to $\mathrm{NO}_{3}$ in a second heated cavity channel. The three $\mathrm{NO}_{3}$ cavity instruments that adopted a broadband approach were also sensitive to other gas-phase absorbers and to aerosol extinction, as discussed in this work.

In this study, we report aerosol extinction coefficient measurements from 15-18, 20, and 21 June 2007 when aerosol was either injected into or produced inside the chamber. Oxidation pathways and SOA formation yields and composition from these experiments have been described previously (Fry et al., 2009, 2011; Rollins et al., 2009). The SAPHIR chamber was equipped with a comprehensive suite of instruments to monitor the gas-phase composition inside the chamber, the chemical and physical properties of aerosols, and environmental variables such as temperature, pressure, and actinic flux. A single vertical $0.5^{\prime \prime}$ i.d. stainless steel transfer line was used to sample from the chamber to the measurement container housing the aerosol instrumentation. In contrast to Teflon, static charge does not build up in a steel line. Particle losses during sampling are expected to be minimal because of the small particle-size $(<250 \mathrm{~nm}$ mode diameter $)$ and because impact losses have not been observed in comparable SOA experiments in the chamber. Particle-size distributions were measured every 7 min using a scanning mobility particle sizer (SMPS, TSI 3936L85) and additionally with an aerosol mass spectrometer (Aerodyne TOF-AMS, 6 min acquisition time). SMPS size distributions were internally corrected for multiply charged particles. The chamber had been purged overnight with synthetic air prior to all experiments; the measurements therefore began in clean, particle-free air with particle number concentrations below $10 \mathrm{~cm}^{-3}$.
The three broadband cavity instruments deployed at the campaign were based on broadband cavity ring-down spectroscopy (BBCRDS, University of Leicester), cavityenhanced differential optical absorption spectroscopy (CEDOAS, University of Heidelberg), and incoherent broadband cavity-enhanced absorption spectroscopy (IBBCEAS, University College Cork). The instruments shared a common measurement methodology: the spectrum of a broadband light source, transmitted through an optically stable cavity, was measured at a spectrograph either as a time-resolved ring-down signal (BBCRDS) or as a time-integrated intensity (CE-DOAS and IBBCEAS). The instrument configurations and the spectral analysis procedures differed and are described in detail below and summarized in Table 1 . To retrieve the aerosol extinction, absorption by $\mathrm{NO}_{3}, \mathrm{H}_{2} \mathrm{O}, \mathrm{NO}_{2}$ and $\mathrm{O}_{3}$ was removed from the sample's total extinction by fitting and then subtracting the instruments' own measured spectral contributions from these gas-phase absorbers (Ball et al., 2004). The BBCRDS instrument was an extractive system located beneath the chamber, while the cavity of the IBBCEAS instrument extended across the full $20 \mathrm{~m}$ length of the chamber in an open path configuration (see Fuchs et al., 2010; Varma et al., 2009). The CE-DOAS instrument was located on the floor inside the chamber and also had an open path cavity. Together, the instruments measured aerosol extinction at wavelengths between 655 and $690 \mathrm{~nm}$ (Table 1). The measurements reported in Sect. 3 are based on experiments when the aerosol extinction inside the chamber was above the instrumental detection limits. The experimental conditions for these days are given in Table 2. The intercomparison of aerosol extinction coefficients is restricted to the $\mathrm{NO}_{3}+\beta$-pinene experiments on 20 and 21 June when all three instruments were operating. 
Table 2. Description of NO3Comp experiments, and indicative values of the maximum aerosol extinction coefficient, for days on which aerosols were added to or formed in the chamber.

\begin{tabular}{llr}
\hline Date & Experiment description & $\mathrm{Max} \varepsilon_{\mathrm{a}}$ \\
\hline 15 June & $\left(\mathrm{NH}_{4}\right)_{2} \mathrm{SO}_{4}$ aerosol $+\mathrm{NO}_{3}$ & $6 \mathrm{Mm}^{-1}$ \\
16, 17 June & Limonene $+\mathrm{NO}_{3}: \mathrm{SOA}_{\text {formation }}$ & $20 \mathrm{Mm}^{-1}$ \\
18 June & Isoprene $+\mathrm{NO}_{3}:\left(\mathrm{NH}_{4}\right)_{2} \mathrm{SO}_{4}$ seed aerosol; SOA formation & $<2 \mathrm{Mm}^{-1}$ \\
20 June & $\beta$-pinene $+\mathrm{NO}_{3}($ dry conditions). SOA formation & $64 \mathrm{Mm}^{-1}$ \\
21 June & $\beta$-pinene $+\mathrm{NO}_{3}(60 \% \mathrm{RH})$. SOA formation & $86 \mathrm{Mm}^{-1}$ \\
\hline
\end{tabular}

\subsection{Broadband cavity ring-down spectroscopy (BBCRDS)}

The BBCRDS technique is based on the simultaneous measurement of wavelength-resolved ring-down transients in a high-finesse optical cavity containing the sample (Bitter et al., 2005; Ball and Jones, 2003; Leigh et al., 2010). Light from a pulsed broadband dye laser $(662 \mathrm{~nm}$ emission maximum with FWHM of $16 \mathrm{~nm}$ ) pumped at $20 \mathrm{~Hz}$ by a frequency-doubled Nd:YAG laser was directed into a $183 \mathrm{~cm}$ long ring-down cavity formed by two highly reflective mirrors (maximum reflectivity, $R_{\max }=99.996 \%$ at $680 \mathrm{~nm}$ ). Although the BBCRDS instrument deployed at SAPHIR was optimized for detection of $\mathrm{NO}_{3}$ via its $662 \mathrm{~nm}$ absorption band (Yokelson et al., 1994), absorption due to $\mathrm{NO}_{2}$ and water vapour and aerosol extinction were also measured within the instrument bandwidth. To preserve the cleanliness of the mirrors' surfaces, the mirror mounts were purged by $0.5 \mathrm{~L} \mathrm{~min}^{-1}$ of dry synthetic air, giving a length through the sample of $1.56 \mathrm{~m}$. The measured extinction was corrected by a length factor, $L_{\mathrm{f}}$ (cf. Eq. 1 below) to account for the sample being excluded from the mirror purge regions. Sample gas was drawn into the cavity (formed inside a $19 \mathrm{~mm}$ internal diameter Teflon tube) through four parallel Teflon tubes $(40 \mathrm{~cm}$ long and $3 \mathrm{~mm}$ internal diameter) which protruded $15 \mathrm{~cm}$ inside the SAPHIR chamber to sample gas uncompromised by wall effects. The sample flow rate was $10 \mathrm{~L} \mathrm{~min}^{-1}$, corresponding to a residence time of $2.7 \mathrm{~s}$ in the instrument. Light exiting the ring-down cavity was dispersed in wavelength by a spectrometer ( $0.36 \mathrm{~nm}$ FWHM spectral resolution) and imaged onto a clocked CCD camera (XCam CCDRem2). The time evolution of individual ring-down events was recorded simultaneously at 512 different wavelengths, corresponding to 512 clocked rows on the CCD camera. Typically, fifty ringdown events were integrated on the CCD camera before the image was read to a computer for processing and storage. Extinction spectra were integrated for $60 \mathrm{~s}$.

The spectrum of the sample's extinction coefficient, $\varepsilon(\lambda)$, was calculated from sets of wavelength-resolved ring-down times measured when the cavity contained the sample, $\tau(\lambda)$, and when back-flushed with dry zero air, $\tau_{0}(\lambda)$ :

$\varepsilon(\lambda)=\frac{L_{\mathrm{f}}}{c}\left(\frac{1}{\tau(\lambda)}-\frac{1}{\tau_{0}(\lambda)}\right)=\sum_{i} \alpha_{i}(\lambda)+\varepsilon_{\mathrm{con}}(\lambda)$, where $L_{\mathrm{f}}$ is the length factor, $c$ is the speed of light, $\alpha_{i}(\lambda)=\sigma_{i}(\lambda)<N_{i}$ are the absorption coefficients of the various fitted molecular absorbers (with absorption cross section $\sigma_{i}$ and number density $N_{i}$ ), and $\varepsilon_{\text {con }}(\lambda)$ is the wavelengthdependent extinction coefficient due to all unstructured contributions to the spectrum (mainly aerosol extinction). Reference ring-down times $\tau_{0}(\lambda)$ were acquired at the start, end, and at least once during a SAPHIR experiment, and $L_{\mathrm{f}}$ was based on fits to the known water vapour content of the chamber (Shillings et al., 2011). In accordance with Eq. (1), the extinction spectra were fitted by reference absorption spectra of $\mathrm{NO}_{3}, \mathrm{H}_{2} \mathrm{O}$ and $\mathrm{NO}_{2}$ and a quadratic polynomial function to account for the unstructured contributions, $\varepsilon_{\operatorname{con}}(\lambda)$. In addition to the aerosol extinction, $\varepsilon_{\mathrm{con}}(\lambda)$ includes (i) instrument artefacts (typically $<5 \mathrm{Mm}^{-1}$ ) due to, for example, degradation in the cavity's alignment caused by temperature variations, and (ii) any molecular absorptions that are unstructured or only very broadly structured over the BBCRDS instrument's bandwidth. Ozone has a weak, but detectable, unstructured absorption, which was subtracted from $\varepsilon_{\operatorname{con}}(\lambda)$ using ozone concentrations measured by the SAPHIR chamber's core instruments; however we cannot exclude the possibility of small additional contributions from unknown molecular absorbers present in the complex gas mixtures generated within SAPHIR. The aerosol extinction coefficient measurements reported here from the BBCRDS instrument are the mean values of $\varepsilon_{\text {con }}(\lambda)$ computed over the wavelength range 655 to $665 \mathrm{~nm}$, after subtraction of any ozone contribution.

\subsection{Cavity-enhanced differential optical absorption spectroscopy (CE-DOAS)}

The CE-DOAS instrument comprised an optical cavity formed by two highly reflective mirrors ( $R=99.9985 \%)$ separated by $0.62 \mathrm{~m}$ (Platt et al., 2009; Meinen et al., 2010). Light from a red LED, stabilized to $27 \pm 2{ }^{\circ} \mathrm{C}$, was focussed into the optical cavity. Light exiting the cavity through the second mirror was coupled into a $400 \mu \mathrm{m}$ quartz fibre $(\mathrm{NA}=0.22)$ of $5 \mathrm{~m}$ length and guided out of the SAPHIR chamber. The fibre was attached alternately to a photomultiplier tube for cavity ring-down measurements or to a spectrograph for intensity measurements.

Ring-down measurements were used to determine the effective length of the light path in the cavity when the chamber 
(and thus the cavity) was free from aerosols and molecular absorbers in the detected wavelength range. In the spectral evaluation range, the mirror reflectivity and thus the light path vary insignificantly and any variation in the light path within the analysed spectral range was ignored. A photomultiplier tube and high-speed current-to-voltage amplifier detected the ring-down signal, which was recorded by a highspeed digitizer. The mean optical path length $L_{0}$ was calculated from the ring-down time. Cavity transmission spectra were recorded by coupling the fibre into an Ocean Optics USB2000 spectrometer with $1.06 \mathrm{~nm}$ spectral resolution. The spectrometer was temperature stabilized to $0.0 \pm 0.1^{\circ} \mathrm{C}$ and each spectrum was acquired over approximately $60 \mathrm{~s}$.

During the campaign, the cavity of the instrument was mounted inside the SAPHIR chamber and placed $0.5 \mathrm{~m}$ above the ground to minimize wall effects. The cavity was located directly in the air flow of the chamber fan and the system was operated in an open path configuration. To avoid degradation of the mirror reflectivity during the measurement, a $5 \mathrm{~L} \mathrm{~min}^{-1}$ synthetic airflow was used to purge the mirrors. The single pass distance through the sample (i.e. the distance between the mirrors excluding the purge length) was $0.50 \mathrm{~m}$. With this configuration, an effective optical path length of about $8.5 \mathrm{~km}$ was attained when the chamber was free of aerosol and absorbing gases.

The spectral evaluation was based on the DOAS principle with additional corrections for the effective length of the light path in the cavity (Platt et al., 2009). A reference spectrum was recorded in the clean chamber (that is, aerosol and absorber-free) before the start of each day's experiment and applied to the trace-gas and aerosol extinction retrieval. For trace-gas analysis, the total measurement time was 5 to 6 min. Reference absorption cross sections of $\mathrm{NO}_{3}, \mathrm{NO}_{2}, \mathrm{O}_{3}$ and $\mathrm{H}_{2} \mathrm{O}$ were fitted to the measured spectrum to retrieve the number densities of these species. To retrieve the aerosol extinction, small molecular absorptions from these species were subtracted from the total extinction over the wavelength interval from 673 to $677 \mathrm{~nm}$. The acquisition time for extinction spectra was about $60 \mathrm{~s}$. The derived trace-gas column densities and absolute absorption were converted to concentrations and aerosol extinction coefficient using Eq. (2). According to Platt et al. (2009), the effective path length, $L_{\text {eff }}$, can be derived from the mean optical path length $L_{0}$ derived from the ring-down measurement and applying a correction.

$\varepsilon(\lambda)=\frac{\ln \left(I / I_{0}\right)}{L_{\text {eff }}}=\frac{\ln \left(I / I_{0}\right)}{L_{0}} \times \frac{\left(I / I_{0}-1\right)}{\ln \left(I / I_{0}\right)}=\frac{\left(I / I_{0}-1\right)}{L_{0}}$

The statistical uncertainty $(1 \sigma)$ for the aerosol extinction measurement was typically about $1 \mathrm{Mm}^{-1}$. The aerosol extinction retrieval requires a stable intensity $I_{0}$; however, the temperature stabilization of the LED was insufficient during this set of experiments and gave rise to an estimated error of about $10 \mathrm{Mm}^{-1}$.

\subsection{Incoherent broadband cavity-enhanced absorption spectroscopy (IBBCEAS)}

The IBBCEAS instrument was customized for use in the SAPHIR chamber, with the optical cavity extending across the full length of the chamber (Varma et al., 2009; Fuchs et al., 2010). The cavity mirrors (reflectivity, $R \sim 0.9984$ at $687 \mathrm{~nm} ;-21 \mathrm{~m}$ radius of curvature; $40 \mathrm{~mm}$ diameter) were separated by $20.13 \mathrm{~m}$, but purging the cavity mirrors to maintain their cleanliness reduced the sample length to $18.3 \pm 0.2 \mathrm{~m}$. Light from a high-radiance short-arc Xe arc lamp was coupled into the cavity, and light transmitted through the cavity was recorded with a monochromator/CCD system (Andor DV401). The instrument's spectral resolution was approximately $0.6 \mathrm{~nm}$ FWHM.

The following procedure was adopted on each day of the campaign. A reference intensity spectrum was measured for several minutes at the start of the day to acquire the baseline intensity spectrum, $I_{0}$, through the clean chamber. The reflectivity of the cavity mirrors was calibrated by inserting a loss-calibrated anti-reflection coated optical flat into the cavity. Subsequently, the cavity transmission spectrum was recorded every $5 \mathrm{~s}$. The extinction coefficient of the sample, $\varepsilon(\lambda)$, is given by Fiedler et al. (2003):

$\varepsilon(\lambda)=\sum_{i} \sigma_{i}(\lambda) N_{i}+\varepsilon_{\operatorname{con}}(\lambda)=\left(\frac{I_{0}}{I}-1\right)\left(\frac{1-R}{L_{\mathrm{s}}}\right)$,

where the cavity's transmitted intensity spectra for the clean and sample-filled chamber are given by $I_{0}(\lambda)$ and $I(\lambda)$, respectively. $L_{\mathrm{s}}$ is the sample length inside the cavity and $R$ is the geometric mean reflectivity of the cavity mirrors. Number densities of $\mathrm{H}_{2} \mathrm{O}, \mathrm{NO}_{3}$, and $\mathrm{NO}_{2}$ were retrieved using a least-squares fit of their respective absorption cross sections to the measured absolute extinction. The small absorption of $\mathrm{O}_{3}$ was corrected using the concentration measurements from the SAPHIR ozone monitor.

The aerosol extinction was retrieved based on the change in the fractional absorption of the $\mathrm{O}_{2} \mathrm{~B}$-band absorption at $687 \mathrm{~nm}$. The fractional absorption changes because aerosol and other extinction processes shorten the effective optical path length through the sample (Varma et al., 2009; Thalman and Volkamer, 2010):

$$
L_{\text {eff }}=\frac{L_{\mathrm{s}}}{1-R+\varepsilon L_{\mathrm{s}}} .
$$

The B-band of $\mathrm{O}_{2}$ is particularly appropriate for this analysis because the concentration and thus the absorption of $\mathrm{O}_{2}$ are constant in the real atmosphere. Fortuitously, absorption by other atmospheric constituents is small at $687 \mathrm{~nm}$, with maximum absorption of $0.6 \mathrm{Mm}^{-1}\left(75 \mathrm{ppbv} \mathrm{NO}_{2}\right.$ ) and $0.6 \mathrm{Mm}^{-1}$ $\left(180 \mathrm{ppbv}_{3}\right)$ in these experiments. The underlying aerosol extinction coefficient, $\varepsilon_{\mathrm{A}}$, can be retrieved directly from the differential absorption as described by Varma et al. (2009):

$\varepsilon_{\mathrm{A}}=\alpha_{\mathrm{O}_{2}}\left(\frac{I}{\Delta I_{\mathrm{O}_{2}}}\right)-\left(\frac{1-R}{L_{\mathrm{s}}}\right)$, 
where $\Delta I_{\mathrm{O}_{2}}$ is the difference between the baseline intensity and the intensity at the absorption maximum of the $\mathrm{O}_{2}$ band, and $\alpha_{\mathrm{O}_{2}}$ is the absorption coefficient of oxygen. We assume that the change in the total extinction (after subtracting the small contribution of gas-phase absorption) arises from aerosol extinction, which is reported for $687.0 \mathrm{~nm}$. Equation (5) notably does not require $I_{0}$ to be known. As a result, the ratio $\left(I / \Delta I_{\mathrm{O}_{2}}\right)$ remains stable even when the lamp intensity $I$ fluctuates.

The rotational structure of the B-band is not resolved by the spectrometer. The question arises as to whether the unresolved fractional absorption of the band changes predictably with the aerosol extinction (Ball and Jones, 2003). To evaluate this issue, a synthetic, high-resolution spectrum of the B-band (Jacquinet-Husson et al., 2011) was calculated for different aerosol extinctions in the cavity and then convolved with the IBBCEAS instrument function. These simulations confirmed that the fractional absorption of the unresolved band scaled linearly with the aerosol extinction within the range of aerosol extinctions reported in this study. Only when $\varepsilon_{\mathrm{A}}$ exceeded $100 \mathrm{Mm}^{-1}$ did the fractional absorption deviate noticeably from linear behaviour. In a second test, the magnitude of the aerosol extinction retrieved using Eq. (5) agreed closely with that observed at $684 \mathrm{~nm}$, a nearby wavelength that was largely free of molecular absorption and hence indicative of the aerosol extinction. This latter approach to estimating the aerosol extinction was highly susceptible to changes in lamp intensity, however, and is not considered further in this study.

\section{Results}

We first compare the aerosol extinction coefficient of ammonium sulfate particles, measured by the IBBCEAS setup, against that calculated from the Mie theory. The aerosol extinction coefficients retrieved by all three instruments are then compared in two experiments in which SOA was formed following the oxidation of $\beta$-pinene by $\mathrm{NO}_{3}$. Figures also show concentrations of $\mathrm{NO}_{3}$ to indicate the chemical processes occurring during the experiments.

\section{Comparison against the Mie theory}

Varying concentrations of polydisperse ammonium sulfate particles were introduced into the chamber during the experiment on 15 June. While the main purpose of this experiment was to test the instruments' abilities to quantify $\mathrm{NO}_{3}$ and $\mathrm{N}_{2} \mathrm{O}_{5}$ in the presence of ammonium sulfate aerosol, it also provided the opportunity to test the ability of the IBBCEAS instrument to quantitatively retrieve aerosol extinction for an aerosol sample of known concentration, particle size and composition. Ammonium sulfate, $\left(\mathrm{NH}_{4}\right)_{2} \mathrm{SO}_{4}$, has well characterised optical properties in the visible and is commonly used for calibrating light scattering instruments

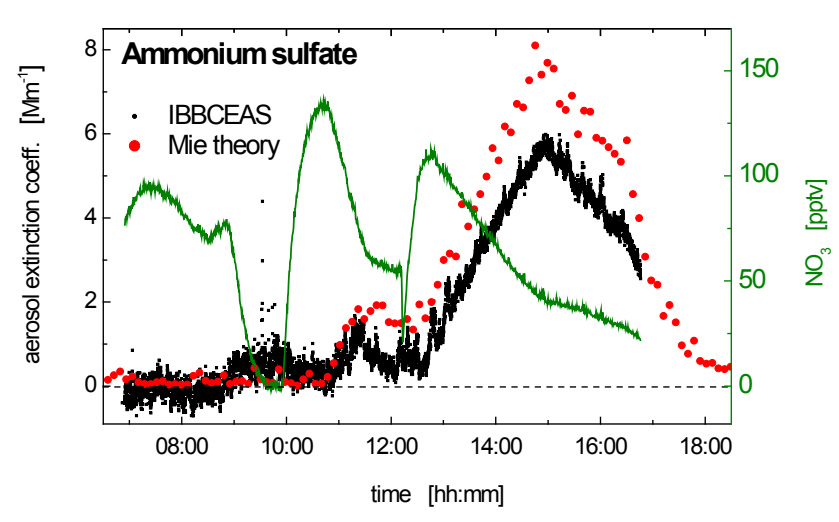

Fig. 1. Ammonium sulfate aerosol extinction coefficient on 15 June 2007 measured by the IBBCEAS instrument at $687 \mathrm{~nm}$ (black dots) and calculated from the Mie theory (red dots) using the measured size distribution. Changes to the chamber composition occurred at 08:55-09:52 (flushing of chamber with clean, humid air); 09:53 (addition of 80 ppbv $\mathrm{O}_{3}$ ); 09:56 (addition of 9 ppbv $\mathrm{NO}_{2}$ ); 10:45-11:25 (addition of $5 \mu \mathrm{g} \mathrm{m}{ }^{-3}$ of $\left(\mathrm{NH}_{4}\right)_{2} \mathrm{SO}_{4}$ aerosol); 12:12 (addition of $9 \mathrm{ppbv} \mathrm{NO}_{2}$ ); and 12:30-14:30 (addition of $12 \mu \mathrm{g} \mathrm{m}^{-3}$ of $\left(\mathrm{NH}_{4}\right)_{2} \mathrm{SO}_{4}$ aerosol).

(Toon et al., 1976; Abo Riziq et al., 2007; Moosmüller et al., 2009; Myhre et al., 2004). Figure 1 compares the extinction coefficient measured by the IBBCEAS instrument at $687 \mathrm{~nm}$ with that calculated from the Mie theory assuming spherical particles (Wickramasinghe, 1973; Bohren and Huffman, 1983; Mätzler, 2002) (BBCRDS and CE-DOAS measurements were not reliable on 15 and 16 June and are not considered in this section). The Mie calculations used the size distributions measured by the SMPS, and assumed that particles had a density of $1.77 \mathrm{~g} \mathrm{~cm}^{-3}$ and a refractive index of $1.52+1 \times 10^{-7} i$ at about $680 \mathrm{~nm}$ (Toon et al., 1976). The real and imaginary parts of the refractive index vary little around these wavelengths. The maximum relative humidity $(\mathrm{RH})$ in the experiment (ca. $60 \% \mathrm{RH}$ ) remained below the deliquescence point of ammonium sulfate $(80 \% \mathrm{RH})$ and the influence of relative humidity was not considered in the Mie calculations (Martin, 2000).

Reasonable agreement was found between the measured and calculated extinction coefficients. A slow upward drift of about $0.7 \mathrm{Mm}^{-1}$ in the measured aerosol extinction is evident prior to introducing aerosol into the chamber. Aerosol was then introduced into the chamber in two steps between 10:45-11:25 and 12:30-14:30 UTC. Two corresponding steps are evident in the measured extinction which broadly agrees with the Mie theory calculation (Fig. 1), although the measured aerosol extinction is about $25 \%$ lower at the extinction maximum $(\sim 15: 00)$ than that calculated from the Mie theory. The difference of $2 \mathrm{Mm}^{-1}$ at this point is not unreasonable, taking into account the precision of the measurements $\left(0.2-0.4 \mathrm{Mm}^{-1}\right.$, see below), a calibration uncertainty of about $0.6 \mathrm{Mm}^{-1}$, and instrument drift of around $1 \mathrm{Mm}^{-1}$. In the latter case we note that the measured 
extinction coefficient is lower than the calculated coefficient by over $1 \mathrm{Mm}^{-1}$ at 12:00 (i.e. before the start of the second, main introduction of aerosol into the chamber). Any errors made in correcting for the absorption of gases would also influence the retrieved aerosol extinction values. Other factors that contribute to the observed difference are due to the uncertainty in the calculated extinction. The latter depends on uncertainties in the measured size distribution, the assumption of spherical particles, the value and extrapolation of the literature refractive index to $687 \mathrm{~nm}$, and the dependence of the refractive index of ammonium sulfate aerosols on humidity (Abo Riziq et al., 2007). There may also have been sampling uncertainties associated with the different locations of the SMPS and IBBCEAS instruments and potential spatial inhomogeneities in the chamber. Taking these several factors into account, we consider the agreement between the measurements and Mie calculations to be satisfactory and to broadly substantiate the reliability of the measured aerosol extinction values.

In the experiment of 16-17 June, SOA was formed from limonene oxidation under dry conditions (dew point $<-44^{\circ} \mathrm{C}$ ) and aged over a period of about $40 \mathrm{~h}$ (Fry et al., 2009). Figure 2 shows the extinction coefficient measured over the two day period. Limonene was introduced in two stages: in the first stage, $10 \mathrm{ppbv}$ of limonene was added to the chamber followed by the addition of $\mathrm{NO}_{2}$ and $\mathrm{O}_{3}$ before 09:00. Formation of $\mathrm{NO}_{3}$ and subsequent oxidation of limonene produced large numbers of small particles, which gradually grew to detectable sizes by around 12:00. A second addition of $\mathrm{NO}_{2}, \mathrm{O}_{3}$, and a further $10 \mathrm{ppbv}$ of limonene around 14:30 increased particle sizes further, resulting in a much stronger increase in the aerosol extinction. The large increase in aerosol extinction following the second limonene addition likely arises through the condensation of oxidation products onto preexisting particles, which causes them to grow to sizes that scatter red light more efficiently. The maximum aerosol extinction coefficient of $20 \mathrm{Mm}^{-1}$ was observed around 19:00, some $4.5 \mathrm{~h}$ after the second introduction of limonene. The subsequent decrease in extinction broadly tracks the decreasing aerosol mass measured by the AMS and is attributable to dilution of the chamber contents and gradual deposition of particles to the chamber walls. Interestingly, the peak in the extinction occurs slightly later (and is rather broader) than the peak in the aerosol mass, presumably because the continued particle growth results in particles that more efficiently scatter red light and thus offset the initial loss of aerosol mass. The chamber was flushed after 18:00 on 17 June, reducing particle concentrations to $<100 \mathrm{~cm}^{-3}$ and leaving an effectively "clean" chamber by 24:00. The SMPS was unfortunately not operating during this experiment and thus the refractive index of the SOA produced by $\mathrm{NO}_{3}+$ limonene oxidation chemistry could not be determined.

The 16-17 June experiment presented an opportunity to evaluate the long-term stability of the IBBCEAS instrument,

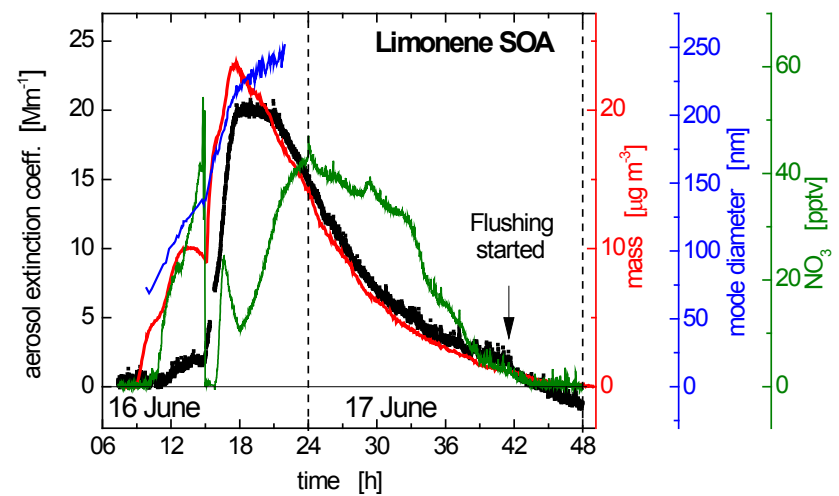

Fig. 2. IBBCEAS measurement of the extinction coefficient of SOA at $687 \mathrm{~nm}$ (black dots) formed by $\mathrm{NO}_{3}$ oxidation of limonene on 16-17 June 2007. Reactants were added to the chamber on 16 June at 06:20 (30 ppbv $\mathrm{NO}_{2}$ ), 06:26 (10 ppbv limonene), 08:50 (50 ppbv $\mathrm{O}_{3}$ ), and 14:30 (30 ppbv $\mathrm{O}_{3}, 30 \mathrm{ppbv} \mathrm{NO}_{2}, 10 \mathrm{ppbv}$ limonene). Total aerosol mass (red) and mode diameter (blue, scaled) from the AMS are also shown. Continuous flushing of the chamber commenced shortly before 18:00 on 17 June, leaving a particle-free chamber by midnight.

which operated over the entire duration of the experiment and relied on a single measurement of $I_{0}$ (Eq. 2) on the morning of 16 June before the start of the experiment. The stability of the instrument can be gauged by a comparison of the extinction measured at the start and end of the experiment in the absence of aerosol, and which should be the same for a stable instrument. The extinction coefficient is marginally below zero (ca. $2 \mathrm{Mm}^{-1}$ ) at the end of the measurements, indicating that the system was exceptionally stable over this extended period.

\section{Intercomparison of aerosol extinction coefficient measurements}

All three broadband cavity spectrometers measured the extinction coefficients of SOA formed following the $\mathrm{NO}_{3}$-initiated oxidation of $\beta$-pinene under dry conditions (20 June) and at $60 \%$ RH (21 June). On both days the chamber was loaded with high- $\mathrm{NO}_{\mathrm{x}}$ and $-\mathrm{O}_{3}$ levels to form $\mathrm{NO}_{3}$ at up to ca. $300 \mathrm{pptv}$ (20 June) and ca. $120 \mathrm{pptv}$ (21 June) (Rollins et al., 2009). $\mathrm{N}_{2} \mathrm{O}_{5}$, formed through the reaction of $\mathrm{NO}_{3}$ and $\mathrm{NO}_{2}$, was also a large reservoir for $\mathrm{NO}_{3}$. Subsequent addition of $15 \mathrm{ppbv} \beta$-pinene to the chamber resulted in a sharp drop in the $\mathrm{NO}_{3}$ concentration, which remained depleted for about an hour before recovering strongly. SOA mass concentrations of 30 to $40 \mu \mathrm{g} \mathrm{m}^{-3}$ were formed during the experiments. No seed particles were added to the chamber on either day. The time series of the aerosol extinction coefficients from the three instruments are shown in Fig. 3a for 20 June and Fig. 4a for 21 June. 

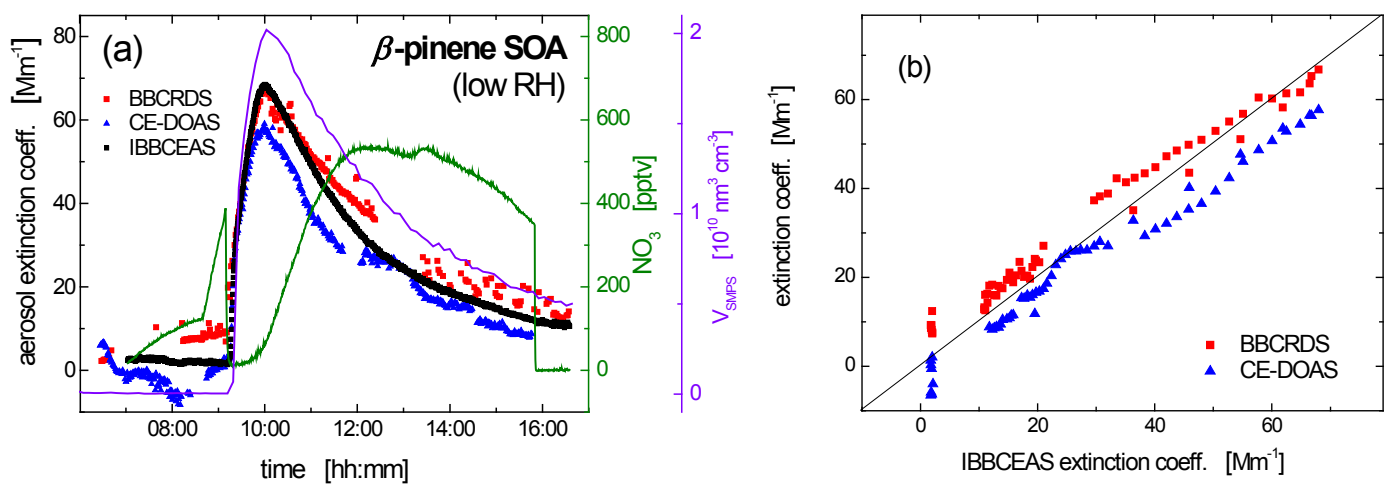

Fig. 3. (a) Time profile of the aerosol extinction coefficient following $\mathrm{NO}_{3}$ oxidation of $\beta$-pinene under dry conditions (20 June). Changes to the chamber composition occurred at 06:27-06:37 (80 ppbv $\mathrm{NO}_{2}$ ), 06:50 (15 ppbv O 3 ), 08:40 (80 ppbv $\mathrm{O}_{3}$ ), and 09:09 (15 ppbv $\beta$-pinene). The $\mathrm{NO}_{3}$ concentration (green) and aerosol volume (violet) are also shown. (b) correlation plots of the aerosol extinction coefficients retrieved by the BBCRDS and CE-DOAS instruments against those from the IBBCEAS measurements. The $1: 1$ line is shown as a solid line.
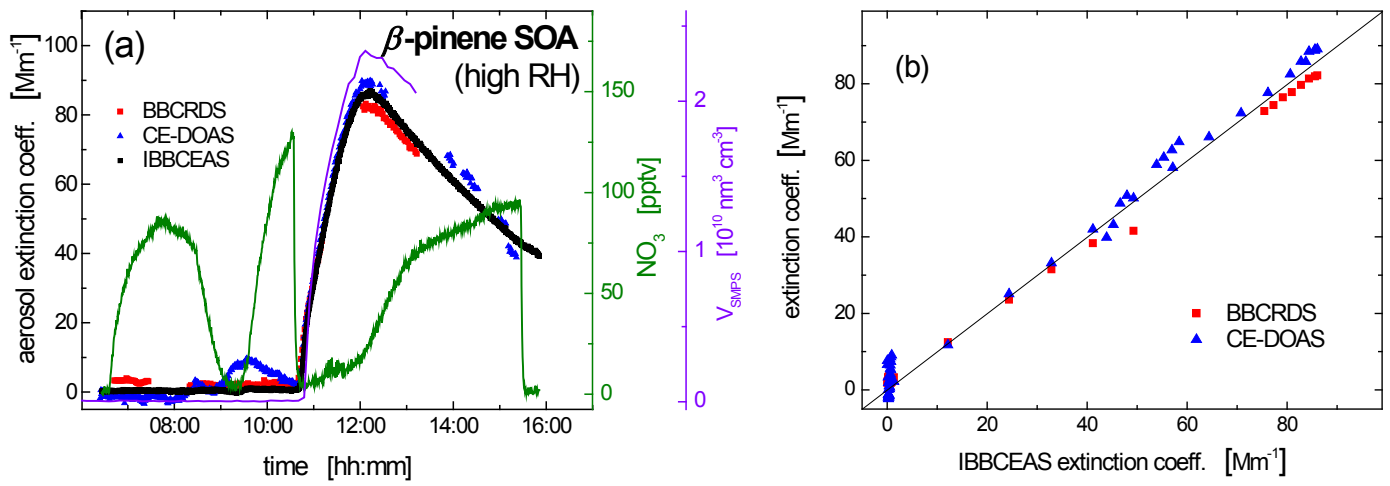

Fig. 4. (a) Time profile of the aerosol extinction coefficients following $\mathrm{NO}_{3}$ oxidation of $\beta$-pinene under humid conditions (21 June). Changes to the chamber composition occurred at 06:23-06:30 (160 ppbv $\mathrm{O}_{3}$ ), 06:35 (1 ppbv NO 2 ), 08:26 (flushed chamber to 60\% RH), 09:24-09:34 (80 ppbv $\mathrm{NO}_{2}$ ), 09:36 (90 ppbv $\mathrm{O}_{3}$ ), and 10:34 (15 ppbv $\beta$-pinene). The $\mathrm{NO}_{3}$ concentration (green) and aerosol volume (violet) are also shown. (b) correlation plots of the aerosol extinction coefficients retrieved by the BBCRDS and CE-DOAS instruments against those from the IBBCEAS measurements. The $1: 1$ line is shown as a solid line.

The precisions of the aerosol extinction coefficient measurements were evaluated before the formation of aerosol in the chamber over uninterrupted periods where each instrument exhibited stable and consistent performance (Table 3). On this basis, the precisions of the CE-DOAS, BBCRDS and IBBCEAS measurements were, respectively, 0.70, 0.37 and $0.25 \mathrm{Mm}^{-1}$ on 21 June for integration times of $60 \mathrm{~s}$ for CEDOAS and BBCRDS and $5 \mathrm{~s}$ for IBBCEAS. Although the periods analysed were mostly longer than $1 \mathrm{~h}$, the above values represent the short-term measurement-to-measurement variability. Significant instrument drift is also evident in the aerosol-free measurements on both days, however. To capture these effects, the mean and standard deviation of the instruments over the entire period before aerosol formation are also included in Table 3. Here, the mean extinction coefficients for the instruments fall between -1.2 and $2.4 \mathrm{Mm}^{-1}$ (with the exception of the BBCRDS measurements on 20 June, which had a larger offset). The stability of this baseline is indicated by the standard deviation, which ranged from 2 to $4 \mathrm{Mm}^{-1}$ for the BBCRDS and CE-DOAS extinction coefficients measurements. These variations in the aerosol-free extinction measurements are less than $6 \%$ of the observed extinction maxima, and demonstrate the importance of acquiring good reference measurements.

On 20 June (Fig. 3), the instruments exhibited very similar temporal behaviour with good agreement observed over the early stages of SOA formation and growth ( 09:10-10:00). The extinction coefficients from the three instruments agree to within $10 \%$ of their mean at the maximum. A change in the performance of the BBCRDS system is evident after approximately 13:30, when occasional mistriggering of the camera with respect to the laser pulse caused the precision to deteriorate and thus the extinction measurements to become more scattered. Variations of up to $7 \mathrm{Mm}^{-1}$ in the responses of the BBCRDS and CE-DOAS instruments are evident in the particle-free chamber (that is, before introduction 
Table 3. Analysis of the extinction coefficients measurements by the three instruments in aerosol-free conditions. Two data sets are analysed: (1) stable operating conditions refers to data when the baseline was stable for an extended time, and is indicative of the measurement precision of the instrument; (2) all aerosol-free conditions describes all the extinction data for each day and provides a measure of system accuracy and instrumental drift. Values are reported as the mean and standard deviation, $1 \sigma$, of the aerosol extinction coefficient for $N$ spectra at the native time resolutions of the instruments $(60 \mathrm{~s}$ for BBCRDS and CE-DOAS, and $5 \mathrm{~s}$ for IBBCEAS).

\begin{tabular}{|c|c|c|c|c|c|}
\hline \multirow[t]{2}{*}{ Instrument } & \multicolumn{2}{|c|}{ Period } & \multirow[t]{2}{*}{$N$} & \multirow{2}{*}{$\begin{array}{r}\text { Mean } \\
\left(\mathrm{Mm}^{-1}\right)\end{array}$} & \multirow{2}{*}{$\begin{array}{l}\sigma \\
\left(\mathrm{Mm}^{-1}\right)\end{array}$} \\
\hline & Date & Time & & & \\
\hline \multicolumn{6}{|c|}{ Stable operating conditions (aerosol-free) } \\
\hline \multirow[t]{2}{*}{ BBCRDS } & 21 Jun & $06: 40-07: 26$ & 29 & 3.2 & 0.36 \\
\hline & & $08: 20-10: 33$ & 72 & 2.1 & 0.37 \\
\hline CE-DOAS & 21 Jun & $06: 13-07: 55$ & 92 & -1.5 & 0.70 \\
\hline \multirow[t]{2}{*}{ IBBCEAS } & 20 Jun & 07:02-09:10 & 1475 & 2.2 & 0.44 \\
\hline & 21 Jun & $06: 26-10: 33$ & 2837 & 0.4 & 0.25 \\
\hline \multicolumn{6}{|c|}{ All aerosol-free conditions } \\
\hline \multirow{2}{*}{ BBCRDS } & 20 Jun & efore 09:10 & 48 & 7.5 & 2.2 \\
\hline & 21 Jun & efore $10: 33$ & 114 & 2.4 & 0.58 \\
\hline \multirow[t]{2}{*}{ CE-DOAS } & 20 Jun & efore 09:10 & 142 & -1.2 & 3.2 \\
\hline & 21 Jun & efore $10: 33$ & 238 & 1.6 & 3.7 \\
\hline \multirow{2}{*}{ IBBCEAS } & 20 Jun 1 & efore $09: 10$ & 1475 & 2.2 & 0.44 \\
\hline & 21 Jun & efore $10: 33$ & 2837 & 0.4 & 0.25 \\
\hline
\end{tabular}

of $\beta$-pinene). In the case of the CE-DOAS measurements, these fluctuations arose from thermal instability of the LED. The same explanation probably applies to the observed undulations in the CE-DOAS aerosol extinction after 11:00 on 20 June.

The agreement between the extinction coefficients values is even better throughout the SOA experiment under humid conditions on 21 June (Fig. 4) and maximum extinction coefficients values agree to within $4 \%$ of their mean. In the $4 \mathrm{~h}$ prior to particle formation, the extinction is very low $\left(<2.5 \mathrm{Mm}^{-1}\right.$ for BBCRDS and $<\sim 0.5 \mathrm{Mm}^{-1}$ for IBBCEAS). The non-zero CE-DOAS values (of up to $9 \mathrm{Mm}^{-1}$ ) over the same period are again attributed to temperature fluctuations of the LED. $\mathrm{NO}_{2}(80 \mathrm{ppbv})$ and $\mathrm{O}_{3}(90 \mathrm{ppbv})$ were added to the chamber at 09:24 and 09:36. No obvious discontinuities in the measured aerosol extinction coefficients of any of the instruments coincide with $\mathrm{NO}_{2}$ and $\mathrm{O}_{3}$ injections into the chamber, indicating that the absorption of $\mathrm{NO}_{2}$ and $\mathrm{O}_{3}$ were properly accounted for in retrieving the aerosol extinction coefficients.

Correlation plots of the BBCRDS and CE-DOAS extinction coefficients against those from the IBBCEAS measurements are shown in Figs. $3 \mathrm{~b}$ and $4 \mathrm{~b}$. The abscissa values are based on the IBBCEAS measurements due to its continuous data set over both experiments and its demonstration of smaller means and instrument drift during the aerosol-free
Table 4. Summary of the correlations of the aerosol extinction coefficients retrieved by BBCRDS and CE-DOAS against that from the IBBCEAS measurements. Data were averaged over the SMPS sampling time.

\begin{tabular}{lcrcc}
\hline Instrument & Slope & $y$ intercept & $R^{2}$ & $N$ \\
\hline \multicolumn{5}{c}{ 20 June (dry) } \\
\hline BBCRDS & 0.90 & $6 \mathrm{Mm}^{-1}$ & 0.9831 & 62 \\
CE-DOAS & 0.88 & $-2 \mathrm{Mm}^{-1}$ & 0.9776 & 60 \\
\hline \multicolumn{7}{c}{ 21 June (humid) } \\
\hline BBCRDS & 0.93 & $2 \mathrm{Mm}^{-1}$ & 0.9983 & 47 \\
CE-DOAS & 1.02 & $1 \mathrm{Mm}^{-1}$ & 0.9910 & 60 \\
\hline
\end{tabular}

initial phases of the 20 and 21 June experiments. To account for the different sampling times, and to facilitate computation of the refractive index discussed below, the extinction coefficients are averaged over the 7 min sampling interval of the SMPS. As is clear from the time profiles for both days, the extinction coefficients from the three instruments are highly correlated. Table 4 summarises the parameters characterising the linear regressions of each correlation. For the data acquired on 20 June, the slopes of the correlation plots are similar for the BBCRDS (0.90) and CE-DOAS (0.88) systems, with respective correlation coefficients, $R^{2}$, of 0.983 and 0.978. Excellent agreement was found between the measurements on 21 June (Fig. 4b), with correlation coefficients of 0.998 (BBCRDS) and 0.991 (CE-DOAS). The slopes for the BBCRDS and CE-DOAS values are respectively 0.93 and 1.02, with small $y$ intercepts.

\section{$\beta$-pinene SOA refractive index}

The refractive index of particles formed by the $\mathrm{NO}_{3}$ oxidation of $\beta$-pinene was calculated from the measured extinction coefficients and aerosol size distributions for both experiments conducted under dry and humid conditions. The refractive index is a complex property $(m=n+i k)$ and both real and imaginary components are usually required. We have assumed here that the SOA generated in our experiments is non-absorbing (i.e. $k=0$ ) because the major constituents of monoterpene SOA - including carboxylic acids, aldehydes, oxy-aldehydes, oxy-carboxylic acids, dicarboxylic acids, and hydroxyl carboxylic acids - do not absorb at the red wavelengths of the present experiments (Kanakidou et al., 2005). Previous studies have found that similar monoterpene SOAs are non-absorbing (Kim et al., 2012; Nakayama et al., 2010; Kanakidou et al., 2005; Lang-Yona et al., 2010; Schnaiter et al., 2005; Lambe et al., 2013). In the specific experiments discussed here, Fry et al. (2009) found that the SOA comprised a large fraction (up to $40-45 \%$ ) of organic nitrates, with possibly some carbonyl groups. Model results suggest that the first generation 
of oxidation chemistry was the only significant nitrate source in the experiment and that subsequent chemistry did not convert nitrate into non-nitrate species. After rapid initial formation of organic nitrates, the fraction of organic nitrates in the particle phase declined gradually over several hours. Neither carbonyls nor organic nitrates absorb appreciably above $350 \mathrm{~nm}$ (Roberts and Fajer, 1989).

Refractive index values were calculated using measurements from each instrument over the half hour of the extinction maximum. The extinction measurements (equally weighted) of the individual instruments were averaged to give a single value for the extinction coefficient; the measured size distributions over this time period were also averaged. The refractive index computed for both experiments was 1.61 . This value is notably larger than previous studies have reported for the refractive indices of monoterpene SOA (Table 5). Assuming a $10 \%$ uncertainty in the mean extinction coefficient (which is representative of the agreement between the instruments and of their stated uncertainties), we estimate an associated uncertainty in the refractive index of \pm 0.03 for both experiments. The time profile of the refractive index (not shown) showed no evolution in the value of the refractive index over the several hours of either experiment.

\section{Discussion}

Although the aerosol extinction measurements reported above share a common approach of measuring the spectrum of broadband light transmitted through an optical cavity, we stress that the measurement methodologies, calibration, and spectral analysis procedures of the systems differed appreciably. In particular, the measurement principle was either based on recording ring-down transients (BBCRDS), or on measuring the time-integrated intensity (CE-DOAS and IBBCEAS). Instrument calibration varied between spectrallydependent ring-down times in zero air (BBCRDS and CEDOAS) and the intensity attenuation by a calibrated low-loss optic (IBBCEAS). In the case of the IBBCEAS system, the aerosol extinction was quantified from the change in the fractional absorption of a molecular absorption band (Eq. 5), as opposed to direct quantification of the continuum extinction underlying the molecular absorption signals measured within the instrument bandwidth (Eq. 3).

For all instruments, the spectral analysis procedure quantified the aerosol extinction by subtracting retrieved (or otherwise known) molecular absorptions from the total measured extinction. The accuracy of the retrieved aerosol extinction obviously depends on the completeness and accuracy of quantifying and removing gas-phase absorption. Sudden changes in the $\mathrm{NO}_{2}, \mathrm{O}_{3}, \mathrm{NO}_{3}$, and $\mathrm{H}_{2} \mathrm{O}$ concentrations during the experiments did not influence the retrieved aerosol extinctions, showing that the absorption of these species was properly accounted for by the three distinct analysis procedures (Dorn et al., 2013). Still, we note that the aerosol
Table 5. Refractive indices of SOA formed from monoterpenes.

\begin{tabular}{|c|c|c|c|}
\hline BVOC precursor & $\begin{array}{l}\text { Reaction } \\
\text { conditions }\end{array}$ & Refractive index, $\lambda$ & Reference \\
\hline$\alpha$-pinene & Ozonolysis & $1.5,700 \mathrm{~nm}$ & $\begin{array}{l}\text { Schnaiter et al. } \\
(2005)\end{array}$ \\
\hline$\alpha$-pinene & $\mathrm{UV} / \mathrm{O}_{3} / \mathrm{NO}_{x}$ & $1.46,700 \mathrm{~nm}$ & Yu et al. (2008) \\
\hline $\begin{array}{l}\text { Holm oak } \\
\text { emissions } \\
\text { (98\% } \\
\text { monoterpenes) }\end{array}$ & Photooxidation & $1.53 \pm 0.08,532 \mathrm{~nm}$ & $\begin{array}{l}\text { Lang-Yona et al. } \\
\text { (2010) }\end{array}$ \\
\hline$\alpha$-pinene & Ozonolysis & $1.41,532 \mathrm{~nm}$ & $\begin{array}{l}\text { Nakayama et al. } \\
(2010)\end{array}$ \\
\hline$\alpha$-pinene & $\begin{array}{l}\mathrm{UV} / \mathrm{NO}_{x} \\
\text { Ozonolysis }\end{array}$ & $1.4-1.5,670 \mathrm{~nm}$ & Kim et al. (2010) \\
\hline$\beta$-pinene & $\left.\begin{array}{l}\mathrm{UV} / \mathrm{NO}_{x} \\
\text { Ozonolysis }\end{array}\right\}$ & $1.43-1.48,670 \mathrm{~nm}$ & \\
\hline$\alpha$-pinene & Ozonolysis & $1.49-1.51,532 \mathrm{~nm}$ & $\begin{array}{l}\text { Redmond and } \\
\text { Thompson } \\
\text { (2011) }\end{array}$ \\
\hline $\begin{array}{l}\text { Limonene } \\
\alpha \text {-pinene }\end{array}$ & $\begin{array}{l}\mathrm{UV} / \mathrm{NO}_{x} \\
\mathrm{UV} / \mathrm{NO}_{x}\end{array}$ & $\begin{array}{l}1.34-1.56,532 \mathrm{~nm} \\
1.36-1.52,532 \mathrm{~nm}\end{array}$ & Kim et al. (2012) \\
\hline$\alpha$-pinene & $\begin{array}{l}\text { Ozonolysis } \\
\text { UV/NO }\end{array}$ & $\begin{array}{r}1.46-1.48,405,532 \mathrm{~nm} \\
1.40-1.41,781 \mathrm{~nm} \\
1.50,405 \mathrm{~nm} \\
1.46,532 \mathrm{~nm} \\
1.42,781 \mathrm{~nm}\end{array}$ & $\begin{array}{l}\text { Nakayama et al. } \\
\text { (2012) }\end{array}$ \\
\hline$\alpha$-pinene & $\begin{array}{l}\mathrm{OH} \text { oxidation } \\
\text { in flow reactor }\end{array}$ & $\begin{array}{l}1.45-1.51,405 \mathrm{~nm} \\
1.42-1.48,532 \mathrm{~nm}\end{array}$ & $\begin{array}{l}\text { Lambe et al. } \\
\text { (2013) }\end{array}$ \\
\hline$\beta$-pinene & $\mathrm{NO}_{3}$ oxidation & $1.61 \pm 0.03,655-687 \mathrm{~nm}$ & This work \\
\hline
\end{tabular}

extinction is an upper limit as any unknown gas-phase absorption would contribute to the (apparent) aerosol extinction. Because so few species absorb at the long visible wavelengths used in these experiments (and no unexplained structured features were present in any of the instruments' fitted spectra), such absorption is expected to be minimal in the extinction measurements reported here.

The extinction coefficients of $\beta$-pinene SOA measured by the three instruments are in good agreement in the two experiments on 20 and 21 June. The extinction measurements are at different wavelengths $(687 \mathrm{~nm}$, and mean over 655 660 and $673-677 \mathrm{~nm}$ ): because the spectral dependence of scattering is expected to be weak over this $30 \mathrm{~nm}$ spread of wavelengths, we consider that these small wavelength differences do not affect the comparability of the measurements. Accurate aerosol extinction measurements are predicated on accurate quantification of the total sample extinction. As the respective $\mathrm{NO}_{2}$ and $\mathrm{NO}_{3}$ intercomparisons show, the concentrations of these species retrieved by the three broadband systems from the molecular absorptions agreed closely with several other techniques (Fuchs et al., 2010; Dorn et al., 2013). The total sample extinction measured by the three systems can therefore be viewed with confidence within the uncertainty limits of the measurements. Moreover, independent evidence for the reliability of the extinction measurements is found in the satisfactory agreement between the measured and calculated ammonium sulfate extinction (taking into account that the extinction was close to the instrument sensitivity).

The performance of the instruments is clearly suited to the study of SOA formation in simulation chambers as this 
work demonstrates for modest concentrations of organic precursor. Based solely on the precision of the extinction coefficient measurements, the respective limits of detection $(3 \sigma)$ of the three systems were respectively $1.2,2.1$, and $1.2 \mathrm{Mm}^{-1}$ for the BBCRDS and CE-DOAS systems over $60 \mathrm{~s}$, and for the IBBCEAS system over $5 \mathrm{~s}$. Other recently developed broadband systems by Washenfelder et al. (2013) and Zhao et al. (2013) have reported somewhat lower precisions of around $0.2 \mathrm{Mm}^{-1}$ (corresponding to a detection limit of $0.6 \mathrm{Mm}^{-1}$ ). These figures represent the best case performance of the instruments and do not take into account any drift in the instruments' baselines. Such instrumental drift was generally a larger source of uncertainty and limited the accuracy at small aerosol extinctions. Engineering improvements since the NO3Comp campaign, including more frequent re-calibration of the baseline spectrum, have produced performances much closer to the best case values (Kennedy et al., 2011). Zhao et al. (2013) report a long-term stability of around $1 \mathrm{Mm}^{-1}$, which is only slightly worse than the detection limit of their instrument. The detection limits we report are well sufficient for monitoring aerosol extinction in polluted atmospheres (for instance, mean aerosol extinction coefficients are $121 \mathrm{Mm}^{-1}$ in Atlanta, and over $300 \mathrm{Mm}^{-1}$ in Beijing) and are possibly low enough for measurements in pristine environments (Carrico et al., 2003; He et al., 2009). If necessary, the detection limits of these broadband systems could be improved by increasing the cavity length or by using higher reflectivity cavity mirrors. As a point of comparison, a recently-developed broadband aerosol extinction spectrometer using a multipass White cell had a higher detection limit of $33 \mathrm{Mm}^{-1}$ (albeit over a very wide spectral range of 250 $700 \mathrm{~nm}$ ) compared to the optical cavity instruments in this work (Chartier and Greenslade, 2012). It should be noted that detection limits of cavity ring-down systems are typically well below $1 \mathrm{Mm}^{-1}$ (Moosmüller et al., 2009); nevertheless, for the broadband instruments, the aerosol extinction is typically obtained in addition to the quantification of trace gases.

The question remains as to the wider application of broadband cavity methods to the optical properties of aerosols. In particular, are these methods sufficiently sensitive and accurate to retrieve the aerosol absorption using the extinctionminus-scattering approach? Many atmospheric aerosols have single scattering albedos (the ratio of scattering losses alone to the aggregate losses from both scattering and absorption) of 0.9 or greater, so extracting the aerosol absorption places stringent demands on the accuracy of both extinction and scattering measurements. A $10 \%$ uncertainty in the aerosol extinction coefficients is representative for the instruments in this study, based on the good agreement of data and their stated uncertainties. Combined with the uncertainty in the measurements of scattering losses, the instruments would thus be suited to the "extinction-minus-scattering" approach for aerosols with appreciable absorption, although for studies interrogating aerosol properties in the laboratory one can use much higher particle concentrations than typically present in ambient air. Reducing the uncertainty in the aerosol extinction would extend the utility of these methods to a wider range of aerosols. Most of the measurement uncertainty of the instruments arises from either the mirror reflectivity calibration or the baseline stability. A more accurate and frequent calibration procedure (as, for example, in Kennedy et al., 2011) could therefore extend their applicability to weakly absorbing aerosols.

A second consideration concerns the prospects for extending the approach to other spectral regions, and particularly to the ultraviolet where the optical properties of aerosols are poorly characterised. A major limitation of the fractional absorption approach used by the IBBCEAS system in this study is that this method is limited to known absorptions at a few wavelengths. Oxygen's absorption bands as used by the IBBCEAS instrument rapidly become weaker at wavelengths further into the visible, and so are probably unusable. However several other absorption bands of well-defined atmospheric gases exist and could be used instead. For instance, Thalmann and Volkamer (2010) have also used this approach based on the absorption of the $\mathrm{O}_{2}$ dimer and $\mathrm{H}_{2} \mathrm{O}$ at 477 and $443 \mathrm{~nm}$, respectively. More generally, broadband optical cavity methods have now been extended into the blue and near-UV region for trace-gas detection (Hoch et al., 2012; Chen and Venables, 2011; Axson et al., 2011; Chen et al., 2011) and several groups have very recently demonstrated instruments for spectrally continuous measurements of aerosol extinction. Washenfelder et al. (2013) studied several scattering, weakly absorbing, and strongly absorbing aerosols between 360 and $420 \mathrm{~nm}$ and developed a procedure to retrieve the complex, wavelength-dependent refractive index of monodisperse aerosols over this spectral region. Wilson et al. (2013) reported the extinction coefficient from 320 to $410 \mathrm{~nm}$ of SOA formed by the photolysis of nitroaromatic compounds in an atmospheric simulation chamber. For field observations, Zhao et al. (2013) have developed an IBBCEAS system for the 445 to $480 \mathrm{~nm}$ spectral region and have demonstrated concurrent measurement of $\mathrm{NO}_{2}$ concentration and aerosol extinction in a polluted urban environment. A key benefit of the Washenfelder, Wilson, and Zhoa instruments, like the broadband spectrometers in the present work, is their ability to acquire wavelength-resolved spectra of the atmosphere extinction and hence the explicit separation of the structured gas-phase and unstructured aerosol contributions. Measures must obviously be taken to ensure that no gas-phase absorption is attributed to aerosol extinction; strategies to accomplish this may include the use of a denuder, or switching between filtered and unfiltered inlet lines. These recent studies underscore the value of sensitive, broadband extinction measurements to characterise the optical properties of atmospheric particles.

This work also reports the first measurement of the refractive index of monoterpene SOA produced primarily by $\mathrm{NO}_{3}$ oxidation. The $\beta$-pinene mixing ratios (15 ppb) and the 
resulting aerosol mass concentrations (30 to $40 \mu \mathrm{g} \mathrm{m}^{-3}$ ) in this work were low compared to other monoterpene SOA refractive index studies (Kim et al., 2010; Nakayama et al., 2010, 2012; Lambe et al., 2013). Kim and Paulsen (2013) note that high-aerosol mass loadings are likely to result in proportionally more high-volatility species in the particle phase, and are thus less representative of ambient aerosols which have lower volatility constituents. The $\beta$-pinene SOA refractive index was $1.61 \pm 0.03$ and did not depend on the humidity, nor did it evolve with aging of the aerosol over several hours. The absence of any humidity effect is consistent with the findings of Fry et al. (2009) that humidity did not influence the SOA yield, density, or proportion of alkyl nitrates in the particle phase for the 20 and 21 June experiments. Previous studies of the refractive index of SOA have not varied humidity outside of a narrow range and provide no point of comparison. Kim et al. (2010) also observed that the refractive index evolved little during ozonolysis of $\alpha$ - and $\beta$-pinene, whereas it increased with aerosol mass concentration during photochemical oxidation of the same compounds. Reporting on the same experiments as us, Fry et al. (2009) found that the SOA mass yield decreased at longer times, suggesting volatilization from the particle phase. This effect was more marked in dry than humid conditions; nevertheless, we observed no associated change in the refractive index.

The $\beta$-pinene SOA refractive indices found in this study are strikingly large. Previous monoterpene SOA studies have reported long wavelength visible refractive indices between 1.38 and 1.56, with most values below 1.5 (Table 5; see also Kim and Paulsen, 2013). Our high-refractive index values also fall outside the range of refractive indices of individual BVOC oxidation products reported by Redmond and Thompson (2011). Kim et al. (2012) found that the refractive indices of limonene and $\alpha$-pinene photooxidation SOA were higher at low $\mathrm{HC} / \mathrm{NO}_{\mathrm{x}}$ ratios. The $\mathrm{HC} / \mathrm{NO}_{\mathrm{x}}$ ratio in our experiments was about $2 \mathrm{ppbC} \mathrm{ppb}^{-1} \mathrm{NO}_{\mathrm{x}}$, which is more than three-fold lower than the reaction conditions in Kim et al. (2012) (6.3-33 ppbC $\left.\mathrm{ppb}^{-1}\right)$. Nevertheless, the highrefractive index values we report are in keeping with the trend in refractive index with $\mathrm{HC} / \mathrm{NO}_{\mathrm{x}}$ ratios that they found. Kim et al. (2012) suggested that the high-refractive index may be associated with either a higher proportion of organic nitrates or with oligomers in the aerosol. While we cannot exclude the possibility of oligomerization in our experiments, the very high proportion (up to $45 \%$, Fry et al., 2009) of organic nitrates produced in these experiments suggests that organic nitrates are the likely cause for the high-SOA refractive index.

A particle's refractive index strongly influences the nature of its interaction with light. High-refractive index $\beta$-pinene SOA particles will scatter light more efficiently than prior SOA studies would suggest. For example, at a refractive index of 1.50 (which is typical of $\mathrm{OH}$ and ozonolysis SOA) the aerosol extinction of the particles in these experiments would be $35 \%$ lower than we observed. Similarly, Kim and co-workers have calculated that changing the SOA refractive index from 1.4 to 1.5 alters radiative forcing by 12 $19 \%$ for non-absorbing aerosol (Kim et al., 2010; Kim and Paulsen, 2013). The results from this study and from Kim et al. (2012) suggest that the high-refractive index seems particularly linked with the products of $\mathrm{NO}_{3}$ oxidation chemistry or relatively high- $\mathrm{NO}_{\mathrm{x}}$ levels. $\mathrm{NO}_{3}$ chemistry occurs primarily at night (although it may also be appreciable in forest canopies during daylight), and recent work has found significant nocturnal particle formation driven by $\mathrm{NO}_{3}$ oxidation of biogenic emissions (Rollins et al., 2012). The optical properties of such $\mathrm{NO}_{3}$-influenced organic aerosol, and their impact on radiative forcing, therefore warrant further study. For nocturnally-produced aerosol, in particular, the evolution of the particles' optical properties would need to be considered over several hours across the transition from night into the daylight conditions of the next day.

Acknowledgements. The $\mathrm{NO}_{3}-\mathrm{N}_{2} \mathrm{O}_{5}$-Intercomparison campaign (2007) was supported by grant number RII3-CT-2004-505968 of the European Community within the 6th Framework Program. Authors associated with University College Cork would like to thank the Irish EPA and Science Foundation Ireland for supporting this work through grants 2005-ET-MS-28-M3, 11/RFP/GEO3200, and 06/RFP/CHP055-STTF09. Authors associated with the Universities of Leicester and Cambridge would like to acknowledge the Natural Environment Research Council for a PhD studentship for AJLS and a grant (NER/T/S/2002/00036) to develop the BBCRDS instrument. Authors associated with the University of Heidelberg thank Thomas Leisner for his input into the project. We also thank personnel at the Forschungszentrum Jülich, particularly Astrid Kiendler-Scharr, Rolf Häseler and Erik Schlosser, for technical and administrative support during the campaign.

Edited by: P. Herckes

\section{References}

Abo Riziq, A., Erlick, C., Dinar, E., and Rudich, Y.: Optical properties of absorbing and non-absorbing aerosols retrieved by cavity ring down (CRD) spectroscopy, Atmos. Chem. Phys., 7, 15231536, doi:10.5194/acp-7-1523-2007, 2007.

Alexander, D. T. L., Crozier, P. A., and Anderson, J. R.: Brown carbon spheres in East Asian outflow and their optical properties, Science, 321, 833-836, 2008.

Andreae, M. O. and Gelencsér, A.: Black carbon or brown carbon? The nature of light-absorbing carbonaceous aerosols, Atmos. Chem. Phys., 6, 3131-3148, doi:10.5194/acp-6-3131-2006, 2006.

Apel, E. C., Brauers, T., Koppmann, R., Bandowe, B., Bossmeyer, J., Holzke, C., Tillmann, R., Wahner, A., Wegener, R., Brunner, A., Jocher, M., Ruuskanen, T., Spirig, C., Steigner, D., Steinbrecher, R., Alvarez, E. G., Muller, K., Burrows, J. P., Schade, G., Solomon, S. J., Ladstatter-Weissenmayer, A., Simmonds, P., Young, D., Hopkins, J. R., Lewis, A. C., Legreid, G., Reimann, S., Hansel, A., Wisthaler, A., Blake, R. S., Ellis, A. M., Monks, P. S., and Wyche, K. P.: Intercomparison of oxygenated volatile 
organic compound measurements at the SAPHIR atmosphere simulation chamber, J. Geophys. Res.-Atmos., 113, D20307, doi:10.1029/2008JD009865, 2008.

Axson, J. L., Washenfelder, R. A., Kahan, T. F., Young, C. J., Vaida, V., and Brown, S. S.: Absolute ozone absorption cross section in the Huggins Chappuis minimum (350-470 nm) at 296 K, Atmos. Chem. Phys., 11, 11581-11590, doi:10.5194/acp11-11581-2011, 2011.

Ball, S. M. and Jones, R. L.: Broad-band cavity ring-down spectroscopy, Chem. Rev., 103, 5239-5262, 2003.

Ball, S. M., Langridge, J. M., and Jones, R. L.: Broadband cavity enhanced absorption spectroscopy using light emitting diodes, Chem. Phys. Lett., 398, 68-74, 2004.

Bergstrom, R. W., Pilewskie, P., Russell, P. B., Redemann, J., Bond, T. C., Quinn, P. K., and Sierau, B.: Spectral absorption properties of atmospheric aerosols, Atmos. Chem. Phys., 7, 5937-5943, doi:10.5194/acp-7-5937-2007, 2007.

Bitter, M., Ball, S. M., Povey, I. M., and Jones, R. L.: A broadband cavity ringdown spectrometer for in-situ measurements of atmospheric trace gases, Atmos. Chem. Phys., 5, 2547-2560, doi:10.5194/acp-5-2547-2005, 2005.

Bohn, B., Rohrer, F., Brauers, T., and Wahner, A.: Actinometric measurements of $\mathrm{NO}_{2}$ photolysis frequencies in the atmosphere simulation chamber SAPHIR, Atmos. Chem. Phys., 5, 493-503, doi:10.5194/acp-5-493-2005, 2005.

Bohren, C. F. and Huffman, D. R.: Absorption and scattering of light by small particles, Wiley, New York, 1983.

Brauers, T., Bossmeyer, J., Dorn, H.-P., Schlosser, E., Tillmann, R., Wegener, R., and Wahner, A.: Investigation of the formaldehyde differential absorption cross section at high and low spectral resolution in the simulation chamber SAPHIR, Atmos. Chem. Phys., 7, 3579-3586, doi:10.5194/acp-7-3579-2007, 2007.

Carrico, C. M., Bergin, M. H., Xu, J., Baumann, K., and Maring, H.: Urban aerosol radiative properties: Measurements during the 1999 Atlanta Supersite Experiment, J. Geophys. Res., 108, 8422, doi:10.1029/2001JD001222, 2003.

Chartier, R. T. and Greenslade, M. E.: Initial investigation of the wavelength dependence of optical properties measured with a new multi-pass Aerosol Extinction Differential Optical Absorption Spectrometer (AE-DOAS), Atmos. Meas. Tech., 5, 709-721, doi:10.5194/amt-5-709-2012, 2012.

Chen, J. and Venables, D. S.: A broadband optical cavity spectrometer for measuring weak near-ultraviolet absorption spectra of gases, Atmos. Meas. Tech., 4, 425-436, doi:10.5194/amt-4-4252011, 2011

Chen, J., Wenger, J. C., and Venables, D. S.: Near-Ultraviolet Absorption Cross Sections of Nitrophenols and Their Potential Influence on Tropospheric Oxidation Capacity, J. Phys. Chem. A, 115, 12235-12242, 2011.

Chen, Y. and Bond, T. C.: Light absorption by organic carbon from wood combustion, Atmos. Chem. Phys., 10, 1773-1787, doi:10.5194/acp-10-1773-2010, 2010.

Dorn, H.-P., Apodaca, R. L., Ball, S. M., Brauers, T., Brown, S. S., Crowley, J. N., Dubé, W. P., Fuchs, H., Häseler, R., Heitmann, U., Jones, R. L., Kiendler-Scharr, A., Labazan, I., Langridge, J. M., Meinen, J., Mentel, T. F., Platt, U., Pöhler, D., Rohrer, F., Ruth, A. A., Schlosser, E., Schuster, G., Shillings, A. J. L., Simpson, W. R., Thieser, J., Tillmann, R., Varma, R., Venables, D. S., and Wahner, A.: Intercomparison of $\mathrm{NO}_{3}$ radical detection instruments in the atmosphere simulation chamber SAPHIR, Atmos. Meas. Tech., 6, 1111-1140, doi:10.5194/amt-6-1111-2013, 2013.

Fiedler, S. E., Hese, A., and Ruth, A. A.: Incoherent broad-band cavity-enhanced absorption spectroscopy, Chem. Phys. Lett. 371, 284-294, 2003.

Forster, P., Ramaswamy, V., Artaxo, P., Berntsen, T., Betts, R., Fahey, D. W., Haywood, J., Lean, J., Lowe, D. C., Myhre, G., Nganga, J., Prinn, R., Raga, G., Schulz, M., and Van Dorland, R.: Changes in Atmospheric Constituents and in Radiative Forcing, in: Climate Change 2007: The Physical Science Basis, Contribution of Working Group I to the Fourth Assessment Report of the Intergovernmental Panel on Climate Change, edited by: Solomon, S., Qin, D., Manning, M., Chen, Z., Marquis, M., Averyt, K. B., Tignor, M., and Miller, H. L., Cambridge University Press, Cambridge, UK and New York, NY, USA, 2007.

Fry, J. L., Kiendler-Scharr, A., Rollins, A. W., Wooldridge, P. J., Brown, S. S., Fuchs, H., Dubé, W., Mensah, A., dal Maso, M., Tillmann, R., Dorn, H.-P., Brauers, T., and Cohen, R. C.: Organic nitrate and secondary organic aerosol yield from $\mathrm{NO}_{3}$ oxidation of $\beta$-pinene evaluated using a gas-phase kinetics/aerosol partitioning model, Atmos. Chem. Phys., 9, 14311449, doi:10.5194/acp-9-1431-2009, 2009.

Fry, J. L., Kiendler-Scharr, A., Rollins, A. W., Brauers, T., Brown, S. S., Dorn, H.-P., Dubé, W. P., Fuchs, H., Mensah, A., Rohrer, F., Tillmann, R., Wahner, A., Wooldridge, P. J., and Cohen, R. C.: SOA from limonene: role of $\mathrm{NO}_{3}$ in its generation and degradation, Atmos. Chem. Phys., 11, 3879-3894, doi:10.5194/acp-113879-2011, 2011.

Fuchs, H., Ball, S. M., Bohn, B., Brauers, T., Cohen, R. C., Dorn, H.-P., Dubé, W. P., Fry, J. L., Häseler, R., Heitmann, U., Jones, R. L., Kleffmann, J., Mentel, T. F., Müsgen, P., Rohrer, F., Rollins, A. W., Ruth, A. A., Kiendler-Scharr, A., Schlosser, E., Shillings, A. J. L., Tillmann, R., Varma, R. M., Venables, D. S., Villena Tapia, G., Wahner, A., Wegener, R., Wooldridge, P. J., and Brown, S. S.: Intercomparison of measurements of $\mathrm{NO}_{2}$ concentrations in the atmosphere simulation chamber SAPHIR during the NO3Comp campaign, Atmos. Meas. Tech., 3, 21-37, doi:10.5194/amt-3-21-2010, 2010.

Fuchs, H., Simpson, W. R., Apodaca, R. L., Brauers, T., Cohen, R. C., Crowley, J. N., Dorn, H.-P., Dubé, W. P., Fry, J. L., Häseler, R., Kajii, Y., Kiendler-Scharr, A., Labazan, I., Matsumoto, J., Mentel, T. F., Nakashima, Y., Rohrer, F., Rollins, A. W., Schuster, G., Tillmann, R., Wahner, A., Wooldridge, P. J., and Brown, S. S.: Comparison of $\mathrm{N}_{2} \mathrm{O}_{5}$ mixing ratios during NO3Comp 2007 in SAPHIR, Atmos. Meas. Tech., 5, 2763-2777, doi:10.5194/amt5-2763-2012, 2012

Hallquist, M., Wenger, J. C., Baltensperger, U., Rudich, Y., Simpson, D., Claeys, M., Dommen, J., Donahue, N. M., George, C., Goldstein, A. H., Hamilton, J. F., Herrmann, H., Hoffmann, T., Iinuma, Y., Jang, M., Jenkin, M. E., Jimenez, J. L., Kiendler-Scharr, A., Maenhaut, W., McFiggans, G., Mentel, Th. F., Monod, A., Prévôt, A. S. H., Seinfeld, J. H., Surratt, J. D., Szmigielski, R., and Wildt, J.: The formation, properties and impact of secondary organic aerosol: current and emerging issues, Atmos. Chem. Phys., 9, 5155-5236, doi:10.5194/acp-9-51552009, 2009. 
He, X., Li, C. C., Lau, A. K. H., Deng, Z. Z., Mao, J. T., Wang, M. H., and Liu, X. Y.: An intensive study of aerosol optical properties in Beijing urban area, Atmos. Chem. Phys., 9, 8903-8915, doi:10.5194/acp-9-8903-2009, 2009.

Hoch, D. J., Buxmann, J., Sihler, H., Pöhler, D., Zetzsch, C., and Platt, U.: A Cavity-Enhanced Differential Optical Absorption Spectroscopy instrument for measurement of $\mathrm{BrO}, \mathrm{HCHO}$, HONO and $\mathrm{O}_{3}$, Atmos. Meas. Tech. Discuss., 5, 3079-3115, doi:10.5194/amtd-5-3079-2012, 2012.

Hoffer, A., Gelencsér, A., Guyon, P., Kiss, G., Schmid, O., Frank, G. P., Artaxo, P., and Andreae, M. O.: Optical properties of humic-like substances (HULIS) in biomass-burning aerosols, Atmos. Chem. Phys., 6, 3563-3570, doi:10.5194/acp-6-3563-2006, 2006.

Jacobson, M. Z.: Isolating nitrated and aromatic aerosols and nitrated aromatic gases as sources of ultraviolet light absorption, J. Geophys. Res.-Atmos., 104, 3527-3542, 1999.

Jacquinet-Husson, N., Crepeau, L., Armante, R., Boutammine, C., Chedin, A., Scott, N. A., Crevoisier, C., Capelle, V., Boone, C., Poulet-Crovisier, N., Barbe, A., Campargue, A., Benner, D. C., Benilan, Y., Bezard, B., Boudon, V., Brown, L. R., Coudert, L. H., Coustenis, A., Dana, V., Devi, V. M., Fally, S., Fayt, A., Flaud, J. M., Goldman, A., Herman, M., Harris, G. J., Jacquemart, D., Jolly, A., Kleiner, I., Kleinbohl, A., Kwabia-Tchana, F., Lavrentieva, N., Lacome, N., Xu, L. H., Lyulin, O. M., Mandin, J. Y., Maki, A., Mikhailenko, S., Miller, C. E., Mishina, T., Moazzen-Ahmadi, N., Muller, H. S. P., Nikitin, A., Orphal, J., Perevalov, V., Perrin, A., Petkie, D. T., Predoi-Cross, A., Rinsland, C. P., Remedios, J. J., Rotger, M., Smith, M. A. H., Sung, K., Tashkun, S., Tennyson, J., Toth, R. A., Vandaele, A. C., and Vander Auwera, J.: The 2009 edition of the GEISA spectroscopic database, J. Quant. Spectrosc. Ra., 112, 2395-2445, 2011.

Kanakidou, M., Seinfeld, J. H., Pandis, S. N., Barnes, I., Dentener, F. J., Facchini, M. C., Van Dingenen, R., Ervens, B., Nenes, A., Nielsen, C. J., Swietlicki, E., Putaud, J. P., Balkanski, Y., Fuzzi, S., Horth, J., Moortgat, G. K., Winterhalter, R., Myhre, C. E. L., Tsigaridis, K., Vignati, E., Stephanou, E. G., and Wilson, J.: Organic aerosol and global climate modelling: a review, Atmos. Chem. Phys., 5, 1053-1123, doi:10.5194/acp-5-1053-2005, 2005.

Kebabian, P. L., Robinson, W. A., and Freedman, A.: Optical extinction monitor using cw cavity enhanced detection, Rev. Sci. Instrum., 78, 063102, doi:10.1063/1.2744223, 2007.

Kennedy, O. J., Ouyang, B., Langridge, J. M., Daniels, M. J. S., Bauguitte, S., Freshwater, R., McLeod, M. W., Ironmonger, C., Sendall, J., Norris, O., Nightingale, R., Ball, S. M., and Jones, R. L.: An aircraft based three channel broadband cavity enhanced absorption spectrometer for simultaneous measurements of $\mathrm{NO}_{3}, \mathrm{~N}_{2} \mathrm{O}_{5}$ and $\mathrm{NO}_{2}$, Atmos. Meas. Tech., 4, 1759-1776, doi:10.5194/amt-4-1759-2011, 2011.

Kim, H. and Paulson, S. E.: Real refractive indices and volatility of secondary organic aerosol generated from photooxidation and ozonolysis of limonene, $\alpha$-pinene and toluene, Atmos. Chem. Phys., 13, 7711-7723, doi:10.5194/acp-13-7711-2013, 2013.

Kim, H., Barkey, B., and Paulson, S. E.: Real refractive indices of alpha- and beta-pinene and toluene secondary organic aerosols generated from ozonolysis and photo-oxidation, J. Geophys. Res.-Atmos., 115, D24212, doi:10.1029/2010jd014549, 2010.
Kim, H., Barkey, B., and Paulson, S. E.: Real Refractive Indices and Formation Yields of Secondary Organic Aerosol Generated from Photooxidation of Limonene and alpha-Pinene: The Effect of the HC/NO ${ }_{x}$ Ratio, J. Phys. Chem. A, 116, 6059-6067, 2012.

Kirchstetter, T. W., Novakov, T., and Hobbs, P. V.: Evidence that the spectral dependence of light absorption by aerosols is affected by organic carbon, J. Geophys. Res., 109, D21208, doi:10.1029/2004JD004999, 2004.

Lambe, A. T., Cappa, C. D., Massoli, P., Onasch, T. B., Forestieri, S. D., Martin, A. T., Cummings, M. J., Croasdale, D. R., Brune, W. H., Worsnop, D. R., and Davidovits, P.: Relationship between Oxidation Level and Optical Properties of Secondary Organic Aerosol, Environ. Sci. Technol., 47, 6349-6357, 2013.

Lang-Yona, N., Rudich, Y., Mentel, Th. F., Bohne, A., Buchholz, A., Kiendler-Scharr, A., Kleist, E., Spindler, C., Tillmann, R., and Wildt, J.: The chemical and microphysical properties of secondary organic aerosols from Holm Oak emissions, Atmos. Chem. Phys., 10, 7253-7265, doi:10.5194/acp-10-7253-2010, 2010.

Leigh, R. J., Ball, S. M., Whitehead, J., Leblanc, C., Shillings, A. J. L., Mahajan, A. S., Oetjen, H., Lee, J. D., Jones, C. E., Dorsey, J. R., Gallagher, M., Jones, R. L., Plane, J. M. C., Potin, P., and McFiggans, G.: Measurements and modelling of molecular iodine emissions, transport and photodestruction in the coastal region around Roscoff, Atmos. Chem. Phys., 10, 11823-11838, doi:10.5194/acp-10-11823-2010, 2010.

Ma, L. L. and Thompson, J. E.: Optical Properties of Dispersed Aerosols in the Near Ultraviolet $(355 \mathrm{~nm})$ : Measurement Approach and Initial Data, Anal. Chem., 84, 5611-5617, 2012.

Martin, S. T.: Phase transitions of aqueous atmospheric particles, Chem. Rev., 100, 3403-3453, 2000.

Martins, J. V., Artaxo, P., Kaufman, Y. J., Castanho, A. D., and Remer, L. A.: Spectral absorption properties of aerosol particles from 350-2500 nm, Geophys. Res. Lett., 36, L13810, doi:10.1029/2009GL037435, 2009.

Massoli, P., Kebabian, P. L., Onasch, T. B., Hills, F. B., and Freedman, A.: Aerosol Light Extinction Measurements by Cavity Attenuated Phase Shift (CAPS) Spectroscopy: Laboratory Validation and Field Deployment of a Compact Aerosol Particle Extinction Monitor, Aerosol. Sci. Tech., 44, 428-435, 2010.

Mätzler, C.: MATLAB Functions for Mie Scattering and Absorption, Research Report No. 2002-08, Institut für Angewandte Physik, Bern, Switzerland, 2002.

Meinen, J., Thieser, J., Platt, U., and Leisner, T.: Technical Note: Using a high finesse optical resonator to provide a long light path for differential optical absorption spectroscopy: CE-DOAS, Atmos. Chem. Phys., 10, 3901-3914, doi:10.5194/acp-10-39012010, 2010.

Mellon, D., King, S. J., Kim, J., Reid, J. P., and Orr-Ewing, A. J.: Measurements of Extinction by Aerosol Particles in the Near-Infrared Using Continuous Wave Cavity Ring-Down Spectroscopy, J. Phys. Chem. A, 115, 774-783, 2011.

Menon, S.: Current uncertainties in assessing aerosol effects on climate, Annu. Rev. Env. Resour., 29, 1-30, 2004.

Miles, R. E. H., Rudic, S., Orr-Ewing, A. J., and Reid, J. P.: Measurements of the wavelength dependent extinction of aerosols by cavity ring down spectroscopy, Phys. Chem. Chem. Phys., 12, 3914-3920, 2010. 
Miles, R. E. H., Rudic, S., Orr-Ewing, A. J., and Reid, J. P.: Sources of Error and Uncertainty in the Use of Cavity Ring Down Spectroscopy to Measure Aerosol Optical Properties, Aerosol Sci. Tech., 45, 1360-1375, 2011.

Moosmüller, H., Varma, R., and Arnott, W. P.: Cavity ring-down and cavity-enhanced detection techniques for the measurement of aerosol extinction, Aerosol Sci. Tech., 39, 30-39, 2005.

Moosmüller, H., Chakrabarty, R. K., and Arnott, W. P.: Aerosol light absorption and its measurement: A review, J. Quant. Spectrosc. Ra., 110, 844-878, 2009.

Myhre, G.: Consistency Between Satellite-Derived and Modeled Estimates of the Direct Aerosol Effect, Science, 325, 187-190, 2009.

Myhre, G., Stordal, F., Berglen, T. F., Sundet, J. K., and Isaksen, I. S. A.: Uncertainties in the radiative forcing due to sulfate aerosols, J. Atmos. Sci., 61, 485-498, 2004.

Nakayama, T., Matsumi, Y., Sato, K., Imamura, T., Yamazaki, A., and Uchiyama, A.: Laboratory studies on optical properties of secondary organic aerosols generated during the photooxidation of toluene and the ozonolysis of alpha-pinene, J. Geophys. Res.Atmos., 115, D24204, doi:10.1029/2010JD014387, 2010.

Nakayama, T., Sato, K., Matsumi, Y., Imamura, T., Yamazaki, A., and Uchiyama, A.: Wavelength dependence of refractive index of secondary organic aerosols generated during the ozonolysis and photooxidation of $\alpha$-pinene, SOLA, 8, 119-123, 2012.

Pettersson, A., Lovejoy, E. R., Brock, C. A., Brown, S. S., and Ravishankara, A. R.: Measurement of aerosol optical extinction at $532 \mathrm{~nm}$ with pulsed cavity ring down spectroscopy, J. Aerosol Sci., 35, 995-1011, 2004.

Platt, U., Meinen, J., Pöhler, D., and Leisner, T.: Broadband Cavity Enhanced Differential Optical Absorption Spectroscopy (CEDOAS) - applicability and corrections, Atmos. Meas. Tech., 2, 713-723, doi:10.5194/amt-2-713-2009, 2009.

Redmond, H. and Thompson, J. E.: Evaluation of a quantitative structure-property relationship (QSPR) for predicting midvisible refractive index of secondary organic aerosol (SOA), Phys. Chem. Chem. Phys., 13, 6872-6882, 2011.

Roberts, J. M. and Fajer, R. W.: UV Absorption Cross-Sections of Organic Nitrates of Potential Atmospheric Importance and Estimation of Atmospheric Lifetimes, Environ. Sci. Technol., 23, 945-951, 1989.

Rohrer, F., Bohn, B., Brauers, T., Bruning, D., Johnen, F. J., Wahner, A., and Kleffmann, J.: Characterisation of the photolytic HONOsource in the atmosphere simulation chamber SAPHIR, Atmos. Chem. Phys., 5, 2189-2201, 2005, http://www.atmos-chem-phys.net/5/2189/2005/.

Rollins, A. W., Kiendler-Scharr, A., Fry, J. L., Brauers, T., Brown, S. S., Dorn, H.-P., Dubé, W. P., Fuchs, H., Mensah, A., Mentel, T. F., Rohrer, F., Tillmann, R., Wegener, R., Wooldridge, P. J., and Cohen, R. C.: Isoprene oxidation by nitrate radical: alkyl nitrate and secondary organic aerosol yields, Atmos. Chem. Phys., 9, 6685-6703, doi:10.5194/acp-9-6685-2009, 2009.

Rollins, A. W., Browne, E. C., Min, K. E., Pusede, S. E., Wooldridge, P. J., Gentner, D. R., Goldstein, A. H., Liu, S., Day, D. A., Russell, L. M., and Cohen, R. C.: Evidence for $\mathrm{NO}_{\mathrm{x}}$ Control over Nighttime SOA Formation, Science, 337, 1210-1212, 2012.
Ruth, A. A., Dixneuf, S., and Raghunandan, R.: Broadband cavity-enhanced absorption spectroscopy with incoherent light, in: Cavity-Enhanced Spectroscopy and Sensing, edited by: Gagliardi, G. and Loock, H. P., Springer, Berlin, 485-517, 2014.

Schnaiter, M., Linke, C., Mohler, O., Naumann, K. H., Saathoff, H., Wagner, R., Schurath, U., and Wehner, B.: Absorption amplification of black carbon internally mixed with secondary organic aerosol, J. Geophys. Res.-Atmos., 110, D19204, doi:10.1029/2005JD006046, 2005.

Shillings, A. J. L., Ball, S. M., Barber, M. J., Tennyson, J., and Jones, R. L.: An upper limit for water dimer absorption in the $750 \mathrm{~nm}$ spectral region and a revised water line list, Atmos. Chem. Phys., 11, 4273-4287, doi:10.5194/acp-11-4273-2011, 2011.

Smith, J. D. and Atkinson, D. B.: A portable pulsed cavity ringdown transmissometer for measurement of the optical extinction of the atmospheric aerosol, Analyst, 126, 1216-1220, 2001.

Strawa, A. W., Castaneda, R., Owano, T., Baer, D. S., and Paldus, B. A.: The measurement of aerosol optical properties using continuous wave cavity ring-down techniques, J. Atmos. Ocean Tech., 20, 454-465, 2003.

Thalman, R. and Volkamer, R.: Inherent calibration of a blue LED-CE-DOAS instrument to measure iodine oxide, glyoxal, methyl glyoxal, nitrogen dioxide, water vapour and aerosol extinction in open cavity mode, Atmos. Meas. Tech., 3, 1797-1814, doi:10.5194/amt-3-1797-2010, 2010.

Thompson, J. E. and Spangler, H. D.: Tungsten source integrated cavity output spectroscopy for the determination of ambient atmospheric extinction coefficient, Appl. Optics, 45, 2465-2473, 2006.

Thompson, J. E., Smith, B. W., and Winefordner, J. D.: Monitoring atmospheric particulate matter through cavity ring-down spectroscopy, Anal. Chem., 74, 1962-1967, 2002.

Toon, O. B., Pollack, J. B., and Khare, B. N.: Optical Constants of Several Atmospheric Aerosol Species - AmmoniumSulfate, Aluminum-Oxide, and Sodium-Chloride, J. Geophys. Res.-Oceans, 81, 5733-5748, 1976.

Varma, R. M., Venables, D. S., Ruth, A. A., Heitmann, U., Schlosser, E., and Dixneuf, S.: Long optical cavities for openpath monitoring of atmospheric trace gases and aerosol extinction, Appl. Optics, 48, B159-B171, 2009.

Venables, D. S., Gherman, T., Orphal, J., Wenger, J. C., and Ruth, A. A.: High sensitivity in situ monitoring of $\mathrm{NO}_{3}$ in an atmospheric simulation chamber using incoherent broadband cavity-enhanced absorption spectroscopy, Environ. Sci. Technol., 40, 6758-6763, 2006.

Washenfelder, R. A., Flores, J. M., Brock, C. A., Brown, S. S., and Rudich, Y.: Broadband measurements of aerosol extinction in the ultraviolet spectral region, Atmos. Meas. Tech., 6, 861-877, doi:10.5194/amt-6-861-2013, 2013.

Wickramasinghe, N. C.: Light scattering functions for small particles, with applications in astronomy, Hilger, London, 1973.

Wilson, E. M., Chen, J., Varma, R. M., Wenger, J. C., and Venables, D. S.: A Novel, Broadband Spectroscopic Method to Measure the Extinction Coefficient of Aerosols in the Near-Ultraviolet, AIP Conf. Proc., 1531, 155-158, 2013. 
Yokelson, R. J., Burkholder, J. B., Fox, R. W., Talukdar, R. K., and Ravishankara, A. R.: Temperature Dependence of the $\mathrm{NO}_{3}$ Absorption Spectrum, J. Phys. Chem., 98, 13144-13150, doi:10.1021/j100101a009, 1994.

Yu, Y., Ezell, M. J., Zelenyuk, A., Imre, D., Alexander, L., Ortega, J., D’Anna, B., Harmon, C. W., Johnson, S. N., and FinlaysonPitts, B. J.: Photooxidation of $\alpha$-pinene at high relative humidity in the presence of increasing concentrations of $\mathrm{NO}_{\mathrm{x}}$, Atmos. Environ., 42, 5044-5060, 2008.
Zhao, W., Dong, M., Chen, W., Gu, X., Hu, C., Gao, X., Huang, W., and Zhang, W.: Wavelength-Resolved Optical Extinction Measurements of Aerosols Using Broad-Band Cavity-Enhanced Absorption Spectroscopy over the Spectral Range of 445-480 nm, Anal. Chem., 85, 2260-2268, 2013. 